\title{
Dissolution of dehydroxylated lizardite at flue gas conditions: III. Near-equilibrium kinetics
}

\author{
Subrahmaniam Hariharan, Mischa Repmann-Werner, Marco Mazzotti* \\ ETH Zurich, Institute of Process Engineering, Sonneggstrasse 3, CH-8092 Zurich, Switzerland
}

\begin{abstract}
The near-equilibrium dissolution kinetics of partially dehydroxylated lizardite was investigated at conditions relevant for ex-situ $\mathrm{CO}_{2}$ mineralization, namely $30{ }^{\circ} \mathrm{C} \leq T \leq 90^{\circ} \mathrm{C}$ and $p \mathrm{CO}_{2}<$ $1 \mathrm{~atm}$. Batch experiments were carefully designed to explore a wide range of operating conditions without precipitating any secondary phases, namely amorphous silica or magnesium carbonates. The operational range included solutions whose compositions were very close to solubility of the dissolving silicate species. Expressions for specific dissolution rates were developed in order to describe the experimentally measured near-equilibrium, non-steady state dissolution profiles. The near-equilibrium kinetic model was able to describe the evolution of the concentration profiles of $\mathrm{Mg}(\mathrm{aq})$ and $\mathrm{SiO}_{2}(\mathrm{aq})$ with good accuracy. A small enhancement in the dissolution rates of forsteritic silicate was observed in the presence of high concentrations of bicarbonate ions. The presence of $\mathrm{Mg}^{2+}$ ions and $\mathrm{SiO}_{2}(\mathrm{aq})$ in the solution were found to affect the specific dissolution rates of the different silicate species present in dehydroxylated lizardite.

Keywords: mineralization, lizardite, dehydroxylation, dissolution, kinetic modeling, equilibrium
\end{abstract}

\section{Introduction}

In this third part of the publication series, we report the experimental results and modeling analysis for the dissolution of partially (75\%) dehydroxylated lizardite (PDL) particles under flue gas atmosphere $\left(\mathrm{CO}_{2}\right.$ partial pressure, $p \mathrm{CO}_{2}$, below $\left.1 \mathrm{~atm}\right)$, at low temperatures $\left(30^{\circ} \mathrm{C} \leq\right.$

\footnotetext{
${ }^{*}$ Corresponding author: phone +41 44632 2456; fax +41 446321141 .

Email address: marco.mazzotti@ipe.mavt.ethz.ch (Marco Mazzotti)
} 
$T \leq 90^{\circ} \mathrm{C}$ ), and at near-equilibrium solution compositions. In the first part of this series, we had reported the experimental results for the dissolution of these particles at far-from-equilibrium conditions under flue gas atmosphere [1]. Experiments were performed in a flow-through reactor at operating conditions that ensured low concentrations of $\mathrm{Mg}(\mathrm{aq})\left(c_{\mathrm{Mg}}\right)$ and $\mathrm{SiO}_{2}(\mathrm{aq})\left(c_{\mathrm{Si}}\right)$. In the second part of the series, we had developed a kinetic model for the dissolution of these particles at far-from-equilibrium conditions [2]. Two different structures of the PDL particles, namely the homogeneous and the heterogeneous particle structures, were considered in the modeling study. PDL particles were assumed to have up to three different silicate species (denoted by the index $j$ ) and each had its characteristic specific dissolution rate $\left(r_{j}\right)$. Kinetic expressions, that are widely used in the literature to describe the specific dissolution rates at steady-state, were used to describe the measured non-steady state dissolution profiles. The far-from-equilibrium study allowed us to empirically describe the evolution of the reaction surface area during particle dissolution. A total of thirteen model parameters were estimated that allowed us to accurately describe the non-steady state and the non-stoichiometric release of $\mathrm{Mg}(\mathrm{aq})$ and $\mathrm{SiO}_{2}(\mathrm{aq})$ at farfrom-equilibrium conditions.

Recently, we had reported experimental evidence of $\mathrm{CO}_{2}$ mineralization with PDL particles at low $p \mathrm{CO}_{2}$ and $T$ [3]. We had shown experimentally that a combined $T$ and $p \mathrm{CO}_{2}$ swing doublestep process can have a higher dissolution and carbonation efficiency than a single-step batch process, under identical dissolution conditions. In the double-step process, PDL particles are dissolved in one reactor operating at solution compositions that are undersaturated with respect to the kinetically relevant magnesium carbonate. This $\operatorname{Mg}(\mathrm{aq})$ rich solution is then pumped into a second reactor, operating at higher $T$ and lower $p \mathrm{CO}_{2}$, wherein the solution becomes supersaturated with respect to the kinetically relevant magnesium carbonate, thus fixing $\mathrm{CO}_{2}$ in solid form as carbonates (see Werner et al. [3] for details).

In this context, we would like, in this work, to describe the dissolution kinetics of PDL particles at conditions relevant for the proposed double-step process, i.e., at $p \mathrm{CO}_{2} \leq 1 \mathrm{~atm}$, at $30^{\circ} \mathrm{C} \leq T \leq 90^{\circ} \mathrm{C}$. The corresponding $\mathrm{pH}, c_{\mathrm{Mg}}$, and $c_{\mathrm{Si}}$ at these conditions are however much higher than those in the far-from-equilibrium kinetics study. The dissolution dynamics at these near-equilibrium solution compositions could be influenced by phenomena that were not considered in our previous far-from-equilibrium kinetic model. These include:

1. different dissolution mechanisms at higher $\mathrm{pH}$ conditions; 
2. inhibition of silicate dissolution rates by $\mathrm{Mg}^{2+}$ ions;

3. reduced chemical affinity for the dissolving species;

4. precipitation of super-saturated secondary phases on the dissolving particles.

The effects of all the phenomena above have been observed and documented in literature (e.g. [47]). A number of studies have recently reported the effect of amorphous silica precipitation on the surface of a dissolving silicate. While the precipitation of amorphous silica was found to strongly inhibit the dissolution kinetics of forsterite [7, 8], it only weakly affects the dissolution kinetics of basalt or wollastonite $[9,10]$. Based on the $c_{\mathrm{Si}}$ values measured in the $\mathrm{CO}_{2}$ mineralization study, we had observed the possibility for the precipitation of amorphous silica at $T \leq 60{ }^{\circ} \mathrm{C}$ and of quartz at $T=90^{\circ} \mathrm{C}$ [3]. However, the precipitation of the silica phases, in those experiments, did not appear to completely inhibit the subsequent $\mathrm{Mg}(\mathrm{aq})$ release into the solution. In general, the consequences of silica precipitation on the transport of reactants and products species across this passivating silica layer is poorly understood and may not be trivial to model. But before trying to understand the consequences of the precipitation of secondary phases during $\mathrm{CO}_{2}$ mineralization, it is very important to have an accurate knowledge of the dissolution kinetics in the absence of secondary phases.

This publication will build upon the far-from-equilibrium modeling work described in Hariharan et al. [2] in order to accommodate the effects of phenomena 1 to 3 listed above. We will first update the specific dissolution rates, $r_{j}$, for the dissolution of the different silicate species at near-equilibrium solution compositions. We then design experiments, that exclude the precipitation of secondary phases, to allow estimation of parameters for the measured values of $r_{j}$. Finally, we discuss the effect of the various solution parameters on the specific dissolution rates.

\section{Theoretical Considerations}

\subsection{Specific Dissolution Rates}

The influence of $\mathrm{pH}, c_{\mathrm{Mg}}$, and $c_{\mathrm{Si}}$ on the dissolution rate of a silicate species can be described through its specific dissolution rate. The specific dissolution rates, $r_{j}$, for the different silicate species $(j=1,2,3)$, considered in our earlier work were descriptive of their far-from-equilibrium kinetics and in mildly acidic solutions [2]. In the following, we will update the expressions of $r_{j}$ for each silicate species. 


\subsubsection{Forsteritic silicate, $j=1$}

In the case of forsteritic silicate, the specific dissolution rate under far-from-equilibrium, acidic conditions was written as [2]:

$$
r_{1}=k_{1} a_{\mathrm{H}^{+}}^{0.5}
$$

where $k_{1}$ is the reaction rate constant for the dissolution of forsteritic silicate under acidic solutions and in the absence of ligands.

Rimstidt et al. performed a comprehensive statistical analysis on forsterite dissolution rates by analyzing all the data that were reported in the literature [11]. They showed that the reaction order with respect to proton activity changes from a value of 0.5 under acidic conditions, to about 0.25 at basic conditions. By extrapolating the rate data at acidic and basic $\mathrm{pH}$ conditions towards neutral $\mathrm{pH}$ conditions, they found that the transition from one mechanism and rate, to the other occurs at a $\mathrm{pH}$ of 5.72. Therefore, the specific dissolution rate of forsteritic silicate in the absence of ligands can be written as

$$
r_{1}= \begin{cases}k_{1} a_{\mathrm{H}^{+}}^{0.5} & \text { if } \mathrm{pH}<5.72 \\ \tilde{k}_{1} a_{\mathrm{H}^{+}}^{0.25} & \text { if } \mathrm{pH}>5.72\end{cases}
$$

where $\tilde{k}_{1}$ is the reaction rate constant for the dissolution of forsteritic silicate in basic solutions and in the absence of any ligands. To ensure continuity of $r_{1}$ across the transition $\mathrm{pH}$, i.e. $\mathrm{pH}^{*}=$ 5.72 , the following constraint

$$
k_{1} a_{\mathrm{H}^{+}}^{*^{0.5}}=\tilde{k}_{1} a_{\mathrm{H}^{+}}^{*^{0.25}}
$$

is imposed which allows calculating $\tilde{k}_{1}$ when $k_{1}$ is known.

Under the conditions relevant for $\mathrm{CO}_{2}$ mineralization reported in Werner et al. [3], the solution has high concentrations of bicarbonate ions. The $\mathrm{pH}$ of the solution, however, is low enough that the concentration of carbonate ions is negligible. Likewise in the surface complexation modeling approach for adsorption of ligands on forsterite surface described in literature $[12,13]$, we assume the adsorption of a bicarbonate ion on a forsteritic silicate site $\mathrm{V}$ to form a ligand-adsorbed site $\mathrm{V}_{\mathrm{x}}$ :

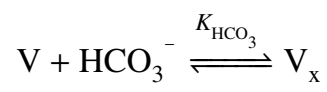

where $K_{\mathrm{HCO}_{3}}$ is the equilibrium constant for the above equilibrium reaction. In order to minimize the number of parameters that need to be estimated, we assume $K_{\mathrm{HCO}_{3}}$ to be temperature- 
independent. The fraction of ligand-adsorbed sites, $\theta_{\mathrm{v}_{\mathrm{x}}}$, is then given by

$$
\theta_{\mathrm{v}_{\mathrm{x}}}=\frac{K_{\mathrm{HCO}_{3}} a_{\mathrm{HCO}_{3}}}{1+K_{\mathrm{HCO}_{3}} a_{\mathrm{HCO}_{3}}}
$$

We assume that a ligand-adsorbed site, $\mathrm{V}_{\mathrm{x}}$, dissolves according to the same mechanism as a free site, V. However, it dissolves at a faster rate (or slower if the ligand is inhibitory) due to a higher (or lower) value of the pre-exponential factor of the reaction rate constant. As the temperature dependence of the rate constants $k$ is described using the standard Arrhenius equation:

$$
k(T)=A \exp \left(-\frac{E_{\mathrm{a}}}{R T}\right),
$$

the assumption above implies that

$$
E_{\mathrm{a}, 1 \mathrm{x}}=E_{\mathrm{a}, 1}
$$

whereas

$$
A_{1 \mathrm{x}} \lessgtr A_{1}
$$

The complete rate expression for the dissolution of forsteritic silicate in the presence of bicarbonate ligands can then be written as the sum of the dissolution rates of the bicarbonate-free and of the bicarbonate-adsorbed sites:

$$
r_{1}= \begin{cases}k_{1} a_{\mathrm{H}^{+}}^{0.5}\left(1-\theta_{\mathrm{v}_{\mathrm{x}}}\right)+k_{1 \mathrm{x}} a_{\mathrm{H}^{+}}^{0.5} \theta_{\mathrm{v}_{\mathrm{x}}} & \text { if } \mathrm{pH}<5.72 \\ \tilde{k}_{1} a_{\mathrm{H}^{+}}^{0.25}\left(1-\theta_{\mathrm{v}_{\mathrm{x}}}\right)+\tilde{k}_{1 \mathrm{x}} a_{\mathrm{H}^{+}}^{0.25} \theta_{\mathrm{v}_{\mathrm{x}}} & \text { if } \mathrm{pH}>5.72\end{cases}
$$

where $k_{1 \mathrm{x}}$ and $\tilde{k}_{\mathrm{1x}}$ are the reaction rate constants for bicarbonate-adsorbed forsteritic silicate sites in acidic and basic solutions, respectively. Again, at the transition $\mathrm{pH}$, i.e. $\mathrm{pH}^{*}=5.72$ :

$$
k_{1 \mathrm{x}} a_{\mathrm{H}^{+}}^{*^{0.5}}=\tilde{k}_{\mathrm{1x}} a_{\mathrm{H}^{+}}^{*^{0.25}}
$$

thus allowing for the calculation of $\tilde{k}_{1 \mathrm{x}}$ when $k_{\mathrm{lx}}$ is known.

The equilibrium for forsterite dissolution can be written as

$$
\mathrm{Mg}_{2} \mathrm{SiO}_{4}(\mathrm{~s})+4 \mathrm{H}^{+} \stackrel{K_{1}}{\rightleftharpoons} 2 \mathrm{Mg}^{2+}+\mathrm{SiO}_{2}(\mathrm{aq})+2 \mathrm{H}_{2} \mathrm{O}
$$


where $K_{1}$ is the corresponding equilibrium constant. The above equilibrium suggests that high values of $c_{\mathrm{Mg}}$ and $c_{\mathrm{Si}}$ should inhibit forsterite dissolution. To our best knowledge, there are no studies in the literature that have experimentally investigated the dissolution kinetics of forsteritic silicate at solution compositions close to its equilibrium. Therefore, we choose to express the reversibility of forsterite dissolution using the conventional approach developed by Aagaard and Helgeson [6], i.e. by updating Eq.(9) as

$$
r_{1}= \begin{cases}\left(k_{1} a_{\mathrm{H}^{+}}^{0.5}\left(1-\theta_{\mathrm{V}_{\mathrm{x}}}\right)+k_{1 \mathrm{x}} a_{\mathrm{H}^{+}}^{0.5} \theta_{\mathrm{v}_{\mathrm{x}}}\right)\left(1-S_{1}^{1 / m}\right) & \text { if } \mathrm{pH}<5.72 \\ \left(\tilde{k}_{1} a_{\mathrm{H}^{+}}^{0.25}\left(1-\theta_{\mathrm{V}_{\mathrm{x}}}\right)+\tilde{k}_{1 \mathrm{x}} a_{\mathrm{H}^{+}}^{0.25} \theta_{\mathrm{V}_{\mathrm{x}}}\right)\left(1-S_{1}^{1 / m}\right) & \text { if } \mathrm{pH}>5.72\end{cases}
$$

where $m$ is the Temkin's average stoichiometric number and $S_{1}$ is assumed to be the saturation index with respect to crystalline forsterite given as:

$$
S_{1}=\frac{a_{\mathrm{Mg}^{2+}}^{2} a_{\mathrm{SiO}_{2}(\mathrm{aq})} a_{\mathrm{H} 2 \mathrm{O}}^{2} a_{\mathrm{H}^{+}}^{-4}}{K_{1}}
$$

\subsubsection{Si-rich species, $j=2$}

In the far-from-equilibrium model, the dissolution mechanism of Si-rich species at $T \leq 90^{\circ} \mathrm{C}$ was assumed to consist of the following set of chemical reactions (note that these equations merely represent the reaction mechanisms and are not stoichiometrically balanced) [2]:

$$
\begin{array}{rll}
>\mathrm{Mg}_{\eta} \mathrm{Si}+2 \eta \mathrm{H}^{+} & \stackrel{K_{\mathrm{ex}}}{\rightleftharpoons} & >\mathrm{Si}(\mathrm{OH})+\eta \mathrm{Mg}^{2+} \\
>\mathrm{Si}(\mathrm{OH}) & \stackrel{K_{\mathrm{des}}}{\rightleftharpoons} & >\mathrm{SiO}^{-}+\mathrm{H}^{+} \\
>\mathrm{Si}(\mathrm{OH})+\mathrm{H}^{+} & \rightleftharpoons & >\mathrm{Si}\left(\mathrm{OH}_{2}\right)^{+}
\end{array}
$$

where $>$ indicates a surface site; $\eta$ is the stoichiometric coefficient, i.e. the number of $\mathrm{Mg}^{2+}$ ions that need to be removed to create one silica precursor complex [5]; $K_{\text {ex }}$ is the equilibrium constant for the leaching of $\mathrm{Mg}^{2+}$ ions by $\mathrm{H}^{+}$ions through an ion-exchange equilibrium process; $K_{\text {des }}$ is the equilibrium constant for the deprotonation of a surface silanol site. For $T \leq 90^{\circ} \mathrm{C}$, $\mathrm{pH} \geq 3.7$, and far-from-equilibrium solution compositions, we had found that $r_{2}$ would only be proportional to the fraction of the deprotonated $>\mathrm{SiO}^{-}$sites, $\theta_{>\mathrm{SiO}}$, whereas the concentration of 
the positively charged site resulting from Eq.(16) is negligible, i.e.

$$
r_{2}=k_{2}^{-} \theta_{>\mathrm{SiO}}
$$

where $k_{2}^{-}$is the rate constant for the dissolution of Si-rich species promoted by deprotonated surface sites [2].

At near-equilibrium solution compositions, the reversible dissolution of the $>\mathrm{SiO}^{-}$sites formed through the reaction given by Eq.(15) can be represented as
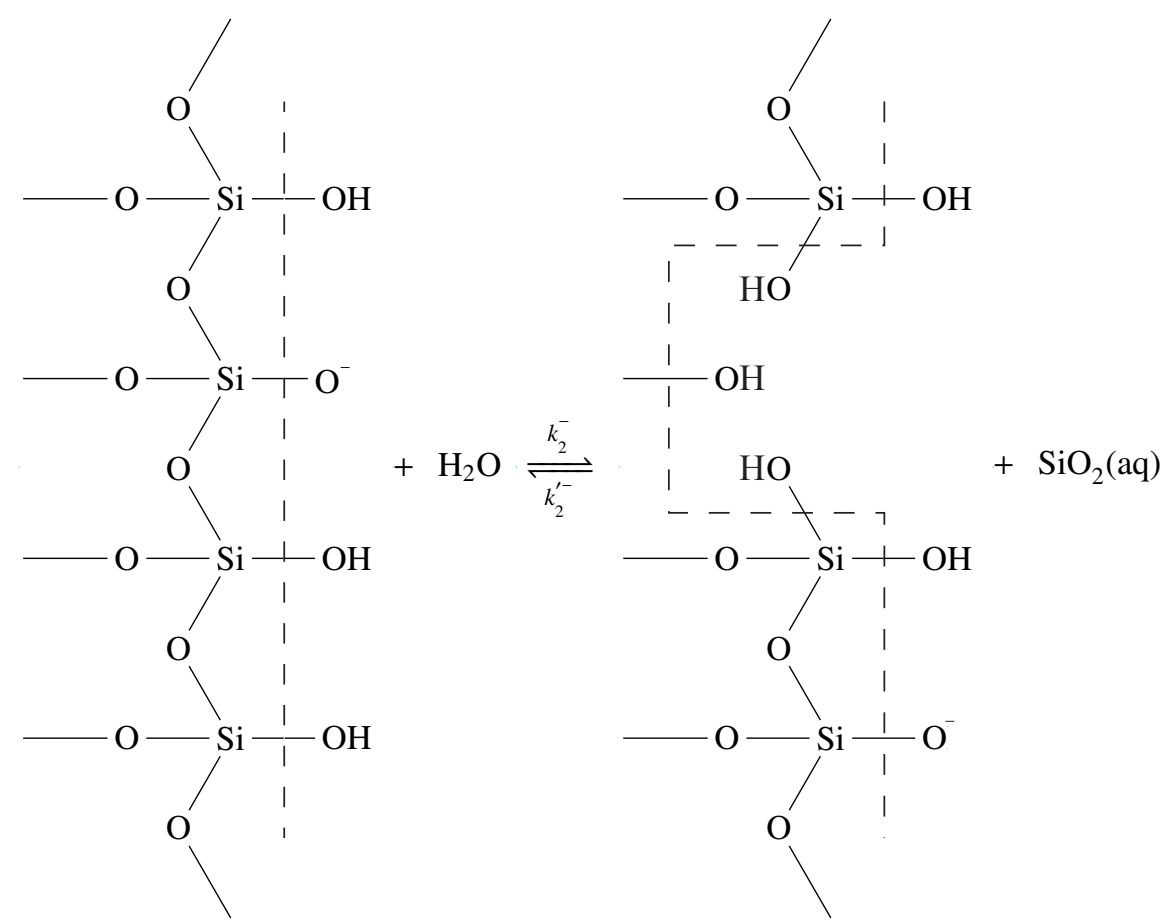

Here the dotted lines represent the interface between the dissolving silicate, on the left, and the aqueous solution, on the right. As an example, the deprotonated surface site, $>\mathrm{SiO}^{-}$, is shown to be connected to neighboring surface silanol groups, $>\mathrm{Si}(\mathrm{OH})$, in Eq.(18). In the forward reaction, the deprotonated surface site undergoes hydrolysis to release $\mathrm{SiO}_{2}(\mathrm{aq})$. The charge of the dissolving surface site is transferred to a neighboring surface silanol, thereby regenerating the active surface site for further dissolution. The reverse reaction involves the condensation of $\mathrm{SiO}_{2}(\mathrm{aq})$ on one of such active sites, i.e. a deprotonated surface silanol site. Such reaction 
mechanism is inspired by what is commonly used to describe the dissolution of amorphous silica in aqueous solutions $[14,15]$.

As the real nature of the Si-rich species, $j=2$, is unknown, we assume the following:

1. the leaching of $\mathrm{Mg}^{2+}$ ions from the silicate species is such that $\eta=1$;

2. the following relationship holds:

$$
\left(k_{2}^{-} / k_{2}^{--}\right)=K_{2}
$$

where $K_{2}$ is assumed to be the equilibrium constant for the dissolution of amorphous silica;

3. $\mathrm{Mg}^{2+}$ ions in solution interact with the surface silanol sites, $>\mathrm{Si}(\mathrm{OH})$, to form bi-nuclear surface site complexes according to:
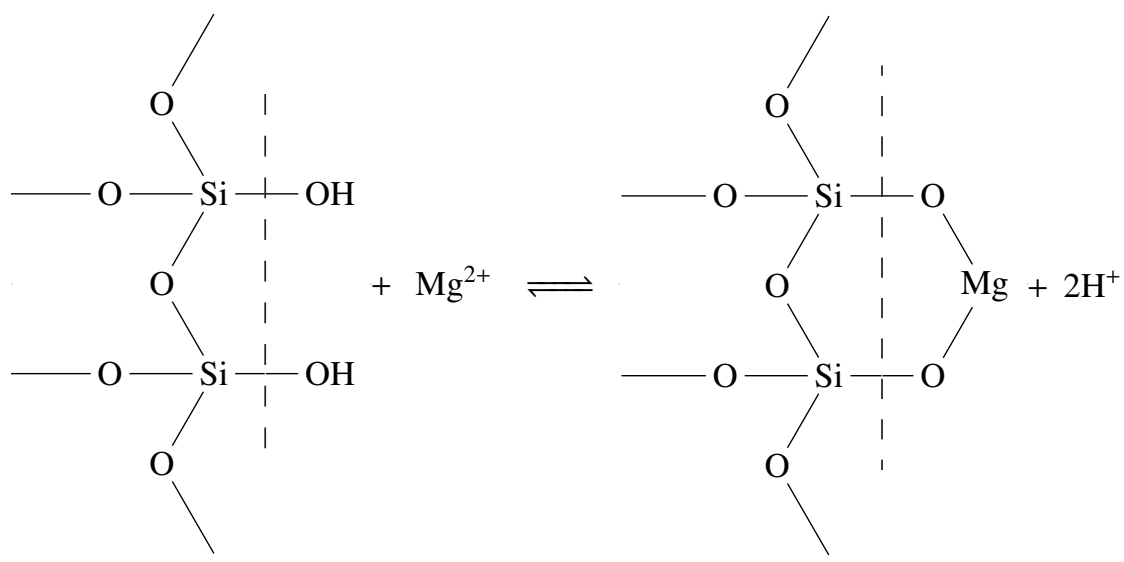

i.e.

$$
>\mathrm{SiOH}+0.5 \mathrm{Mg}^{2+} \stackrel{K_{\text {inh }}}{\rightleftharpoons}>\mathrm{SiO}\left(\mathrm{Mg}^{2+}\right)_{0.5}+\mathrm{H}^{+}
$$

where $K_{\text {inh }}$ is the equilibrium constant for the above equation and is assumed to be temperatureindependent. Bi-nuclear complexes formed by multivalent cations and ligands are known to inhibit the dissolution $[13,16]$, hence we assume that the bi-nuclear complex $>\mathrm{SiO}\left(\mathrm{Mg}^{2+}\right)_{0.5}$ has negligible dissolution rate.

Therefore, the reversible dissolution of the Si-rich species can be written as:

$$
r_{2}=\left(k_{2}^{-} \theta_{>\mathrm{SiO}^{-}}\right)-\left(k_{2}^{\prime-} a_{\mathrm{SiO}_{2}(\mathrm{aqq})} \theta_{>\mathrm{SiO}}^{-}\right)
$$


or,

$$
r_{2}=k_{2}^{-} \theta_{>\mathrm{SiO}^{-}}\left(1-\frac{a_{\mathrm{SiO}_{2}(\mathrm{aaq})}}{K_{2}}\right)
$$

or,

$$
r_{2}=k_{2}^{-} \theta_{>\mathrm{SiO}}^{-}\left(1-S_{2}\right)
$$

where $S_{2}$ is the saturation index with respect to amorphous silica, and $\theta_{>\mathrm{SiO}^{-}}$is given by (see Appendix B in Hariharan et al. [2] for an equivalent derivation for the surface site fraction):

$$
\theta_{>\mathrm{SiO}}=\frac{K_{\mathrm{des}} / a_{\mathrm{H}^{+}}}{1+\frac{K_{\mathrm{des}}}{a_{\mathrm{H}^{+}}}+\frac{1}{K_{\mathrm{ex}}}\left(\frac{a_{\mathrm{Mg}^{2+}}}{a_{\mathrm{H}^{+}}^{2}}\right)+K_{\mathrm{inh}}\left(\frac{a_{\mathrm{Mg}^{2+}}}{a_{\mathrm{H}^{+}}^{2}}\right)^{0.5}}
$$

The temperature dependence of $K_{\mathrm{ex}}$ is described using the integrated form of the Van't Hoff equation:

$$
K_{\text {ex }}(T)=K_{\text {ex }}\left(T_{\text {ref }}\right) \exp \left(-\frac{\Delta H_{\text {ex }}^{0}}{R}\left(\frac{1}{T}-\frac{1}{T_{\text {ref }}}\right)\right)
$$

where $\Delta H_{\text {ex }}^{0}$ is the corresponding enthalpy of reaction and $T_{\text {ref }}=298.15 \mathrm{~K}$.

\subsubsection{Lizardite, $j=3$}

Lizardite is present in smaller amounts only in the core of PDL particles in the case of a heterogeneous particle structure [2]. The far-from-equilibrium dissolution kinetics of lizardite at acidic $\mathrm{pH}$ conditions was described as:

$$
r_{3}=k_{3} a_{\mathrm{H}^{+}}^{0.5}
$$

The above expression has been shown to be valid at $\mathrm{pH} \leq 6.7$ and temperatures $27^{\circ} \mathrm{C} \leq T \leq$ $90^{\circ} \mathrm{C}$ [17]. The effect of a higher $\mathrm{pH}$ or $\mathrm{Mg}(\mathrm{aq})$ concentrations on the dissolution rates of lizardite is not clearly established. For simplicity, we do not fit any new parameters for $r_{3}$, but only account for its equilibrium limitation through:

$$
r_{3}=k_{3} a_{\mathrm{H}^{+}}^{0.5}\left(1-S_{3}\right)
$$


where $S_{3}$ is the saturation index with respect to lizardite, given by

$$
S_{3}=\frac{a_{\mathrm{Mg}^{2+}}^{3} a_{\mathrm{SiO}_{2}(\mathrm{aq})}^{2} a_{\mathrm{H} 2 \mathrm{O}}^{5} a_{\mathrm{H}^{+}}^{-6}}{K_{3}}
$$

with $K_{3}$ being the equilibrium constant for the dissolution of crystalline lizardite which is written as:

$$
\mathrm{Mg}_{3} \mathrm{Si}_{2} \mathrm{O}_{5}(\mathrm{OH})_{4}(\mathrm{~s})+6 \mathrm{H}^{+} \stackrel{K_{3}}{\rightleftharpoons} 3 \mathrm{Mg}^{2+}+2 \mathrm{SiO}_{2}(\mathrm{aq})+5 \mathrm{H}_{2} \mathrm{O}
$$

\subsection{Reactor modeling}

The evolution of the instantaneous concentration of either solute $\left(\mathrm{Mg}(\mathrm{aq})\right.$ or $\left.\mathrm{SiO}_{2}(\mathrm{aq})\right)$ in a well-stirred batch reactor can be written as:

$$
\frac{\mathrm{d}\left(c V_{\mathrm{r}}\right)}{\mathrm{d} t}=-\frac{\mathrm{d} N}{\mathrm{~d} t}
$$

where $V_{\mathrm{r}}$ is the mass of water in the reactor, $c$ is the concentration of the aqueous solute, and $N$ is the total number of moles of that solute still in the solid particles at time $t$. The expressions relating $N$ to $r_{j}$ are the same as in the far-from-equilibrium model, given by Eqs. 13, 14, 26 and 29 in Hariharan et al. [2].

\section{Experimental}

\subsection{Materials}

PDL particles were obtained from Shell Global Solutions International as a milled sub $125 \mu \mathrm{m}$ powder, which was found to have a very broad particle size distribution with a large fraction of fines. It was therefore sieved to a narrower and well-defined $20-63 \mu \mathrm{m}$ particle size fraction. Detailed characterization of both these particle size fractions are reported elsewhere $[1,3]$. Gas bottles of pure $\mathrm{CO}_{2}$ (grade 4.5), calibrated gas mixtures of $50 \mathrm{~mol} \%, 10 \mathrm{~mol} \%$, and $2.5 \mathrm{~mol} \% \mathrm{CO}_{2}$ in $\mathrm{N}_{2}( \pm 2 \%$ relative error, Pangas AG, Switzerland) were used to obtain different gas phase compositions for the dissolution experiments. Ultrapure de-ionized water (Millipore, $18.2 \mathrm{M} \Omega \mathrm{cm}$ ) was used as the solvent for all dissolution experiments. Some dissolution experiments were also performed in a $10 \mathrm{mmol} \mathrm{kg}{ }^{-1} \mathrm{Na}^{+}$solution prepared from ultrapure de-ionized water and $\mathrm{NaHCO}_{3}$ salt (Merck KGaA, Germany). 


\subsection{Experimental set-up and methods}

Isothermal batch dissolution experiments were performed on an EasyMax ${ }^{\mathrm{TM}}$ synthesis workstation (Mettler Toledo, Switzerland). A $140 \mathrm{~mL}$ PTFE reactor was used instead of the standard glass reactors that are provided with the workstation in order to limit solute-wall interactions. The temperature of the reactor was controlled well within $\pm 0.1^{\circ} \mathrm{C}$ of the set-temperature during all the experiments. The reactor lid (also made of PTFE) hosts an overhead stirrer attached to an upward pitched (at $45^{\circ}$ ) four-bladed impeller and has ports for a thermocouple, a gas-dip tube, a reflux-condenser, a conductivity probe (InLab ${ }^{\circledR} 731$ connected to SevenMulti ${ }^{\mathrm{TM}}$, Mettler Toledo, Switzerland), and a port to load the PDL particles or to take samples. The gas flow rate was controlled to about $50 \mathrm{~mL} \mathrm{~min}^{-1}$ via rotameters, and the online solution conductivity was continuously recorded by a computer. The experiments were performed at atmospheric pressure conditions, which is assumed to be $1 \mathrm{~atm}$. A small amount of solution was continuously lost from the reactor due to gas bubbling; such loss was neglected.

The conductivity probe was calibrated in order to track the evolution of $c_{\mathrm{Mg}}$ in the reactor continuously during dissolution. The details of the conductivity probe calibration are provided in Appendix A. The use of an online $\mathrm{pH}$ probe to track the evolution of cations during mineral dissolution is unreliable due to the non-reproducible effects of stirring on $\mathrm{pH}$ measurement $[18$, 19]. On the other hand, stirring speed did not have any effect on the measured conductivity values during any experiment. However, solution conductivity measurements can be affected if solid particles or gas bubbles flow between the electrodes. The experiments performed in this study employed very low slurry densities $(\leq 0.53 \%)$ of small particle sizes which were verified not to affect the conductivity measurements. The conductivity probe was positioned above the impeller so that the circulating fluid avoided the accumulation of gas bubbles on the electrodes. The gas-dip tube was also suitably positioned to avoid the passage of gas-bubbles between the electrodes of the conductivity probe.

Dissolution experiments were performed at 30,60 , and $90^{\circ} \mathrm{C}$. Experiments were performed either in $10 \mathrm{mmol} \mathrm{kg}^{-1} \mathrm{NaHCO}_{3}$ solutions, or in ultrapure de-ionized water, or in a $\mathrm{Mg}(\mathrm{aq})$ rich solution obtained by dissolving synthetic magnesium carbonate, or in a $\mathrm{Mg}(\mathrm{aq})$ and $\mathrm{SiO}_{2}(\mathrm{aq})$ rich solution obtained from the filtrate of pre-dissolved PDL slurry solution. In all experiments, a standard operating procedure was strictly followed that allowed us to obtain reproducible experimental results. Fig. 1 shows the evolution of $c_{\mathrm{Mg}}, c_{\mathrm{Si}}$, and of the solution conductivity, $\kappa$, 
during one exemplary experiment. Each experiment consisted of three experimental runs (data shown by colors red, blue, and green in Fig. 1). The first experimental run (data in red) starts by taking $95 \mathrm{~g}$ of a known solution in the reactor and equilibrating it to the desired temperature (T) and gas composition $\left(f_{\mathrm{CO}_{2}}\right)$ for exactly one hour $(-60 \mathrm{~min} \leq t \leq 0 \mathrm{~min}$ in Fig. 1). Since the conductivity value is affected by both $T$ and aqueous ionic species, a constant value of the measured conductivity for an extended period of time indicates a solution at equilibrium. One hour of equilibration time was found to be more than enough for all the experiments performed in this study. A known mass, $w$, of PDL particles was then loaded into the reactor (at $t=0$ ). The changing values of the measured conductivity over time indicates the release of $\operatorname{Mg}(\mathrm{aq})$ during dissolution. The initial decrease in the conductivity at the onset of dissolution is due to depletion of protons (protons have a much higher conductivity than other ions present in this system). Although the conductivity probe could track the evolution of $c_{\mathrm{Mg}}$ in the solution, $c_{\mathrm{Si}}$ can only be measured offline by means of manual sampling. Hence, at $t=60 \mathrm{~min}$, a representative sample of the reactor slurry solution $(\approx 10 \mathrm{~mL})$ was withdrawn using a syringe. The solution was immediately filtered and if needed, the filtrate was diluted. $\mathrm{SiO}_{2}(\mathrm{aq})$ concentrations were determined photospectrometrically using the molybdenum blue method. In order to further validate the conductivity measurements, $\operatorname{Mg}(\mathrm{aq})$ concentrations in the samples were measured using an ion-exchange chromatography system (ICS2000, Dionex). The measured reactor concentrations $c_{\mathrm{Mg}}$ and $c_{\mathrm{Si}}$ at $t=60 \mathrm{~min}$ are shown in Fig. 1 . The comparison of the measured $c_{\mathrm{Mg}}$ concentrations and those obtained from conductivity measurements is also shown in Fig. 1.

Preliminary test experiments showed that the withdrawal of such a high volume fraction of the reactor solution affected the subsequent dissolution dynamics in a non-reproducible way. Therefore, it was decided to stop the first experimental run after sampling and to start the second and the third experimental runs by following the exact same procedure. The second and the third experimental runs were then allowed to run until $t=120 \mathrm{~min}$ (data shown in blue) and until $t=180 \mathrm{~min}$ (data shown in green), respectively. While this operating procedure is time consuming, it allowed us to measure the solution composition accurately and to validate the experimental reproducibility by comparing the conductivity profiles of each experimental run triplet. In all our experiments, the conductivity profiles overlapped very well thus proving good reproducibility. Based on the measured $c_{\mathrm{Mg}}$ and $c_{\mathrm{Si}}$ values, the extents of dissolution, $X_{\mathrm{Mg}}$ and $X_{\mathrm{Si}}$, were calculated. Thirty experiments were performed in this study at various operating conditions, as 
listed in Table 1. Experiments DB1 - DB9 and DB10 - DB18 explore dissolution kinetics at low solid loadings ( $w=10 \mathrm{mg}$, corresponding to $0.105 \mathrm{mg}$ PDL/g solution) in bicarbonate-rich and bicarbonate-lean solutions, respectively. Experiments DB19 - DB30 study the dissolution behavior at higher $c_{\mathrm{Mg}}$ or $c_{\mathrm{Si}}$ values. Based on the equations described in Section 2.1, the four variables representing the solution composition that influence the specific dissolution rates are 1) the solution $\mathrm{pH}$, or $\left.a_{\mathrm{H}^{+}}, 2\right) a_{\mathrm{HCO}_{3}}$ through $\left.\theta_{\mathrm{v}_{\mathrm{x}}}, 3\right)$ the activity ratio term $\left(a_{\mathrm{Mg}^{2+}} / a_{\mathrm{H}^{+}}^{2}\right)$, and 4$)$ the saturation indices $S_{j}$. The thirty experiments performed in this study span a wide range of values of these four solution parameters and measure the dissolution kinetics of PDL particles without precipitating secondary phases.

Besides the initial solution compositions, the maximum values of the theoretical $\mathrm{pH}$, the activity ratio $\left(a_{\mathrm{Mg}^{2+}} / a_{\mathrm{H}^{+}}^{2}\right), \theta_{\mathrm{v}_{\mathrm{x}}}$ and $S_{j}$ attained in each experiment are also tabulated in Table 1 . The fugacity of $\mathrm{CO}_{2}, f_{\mathrm{CO}_{2}}$, was calculated from the Redlich-Kwong equation of state as described elsewhere [1]. $\mathrm{CO}_{2}-\mathrm{H}_{2} \mathrm{O}$ equilibrium was assumed for all simulations, and the validity of this assumption is discussed below. All activities, $a$, and saturation indices, $S_{j}$, in this study were computed using the geochemical equilibrium software package, EQ3/6 v8.0a, with the $y m p$ database and B-dot equation to determine the activity coefficients of the aqueous species [20]. Due to the lack of thermodynamic solubility data for lizardite in the ymp database, the solubility product $K_{3}$ for lizardite at different temperatures $T$ were set equal to those of chrysotile, a polymorph of lizardite. Such an assumption was also made in a recent study, where the dissolution kinetics of lizardite was investigated [17].

In order to validate the assumption of perfect $\mathrm{CO}_{2}-\mathrm{H}_{2} \mathrm{O}$ equilibrium, selected experiments were repeated with a pH probe (HA405-DXK, Mettler Toledo, Switzerland) instead of the conductivity probe. The qualitative trends of the experimental $\mathrm{pH}$ profiles could be used to determine the validity of the $\mathrm{CO}_{2}-\mathrm{H}_{2} \mathrm{O}$ equilibrium assumption in the experiments. A quantitative comparison however, is not possible due to the aforementioned issues associated with an online $\mathrm{pH}$ probe. It was also not possible to use both the conductivity and the $\mathrm{pH}$ probe simultaneously as online tools, because the $\mathrm{pH}$ probe constantly releases trace amounts of a certain ionic species (possibly $\mathrm{KCl}$ ) into the solution, thus disturbing the conductivity measurements. 


\section{Results and Discussions}

The experimentally measured $c_{\mathrm{Mg}}$ and $c_{\mathrm{Si}}$ profiles from experiments DB1 - DB18 were used to estimate the six unknown parameters, namely $A_{1 \mathrm{x}}, K_{\mathrm{HCO}_{3}}, m, K_{\mathrm{ex}}\left(25^{\circ} \mathrm{C}\right), \Delta H_{\mathrm{ex}}^{0}$, and $K_{\mathrm{inh}}$, associated to the updated expressions for the specific dissolution rates. The values for the other parameters in the dissolution model are the same as those in the far-from-equilibrium model [2], and these are also tabulated in Table S1. The six parameters were estimated for both the homogeneous and the heterogeneous particle structures. These eighteen experiments were chosen for parameter estimation because:

1. they cover a wide range of values of $\mathrm{pH}, \theta_{\mathrm{v}_{\mathrm{x}}}$, activity ratio $\left(a_{\mathrm{Mg}^{2+}} / a_{\mathrm{H}^{+}}^{2}\right)$, and saturation indices $S_{j}$.

2. the solid loadings, $w$, are low so that the assumption of perfect $\mathrm{CO}_{2}-\mathrm{H}_{2} \mathrm{O}$ equilibrium is valid, as qualitatively proven by the experimentally measured $\mathrm{pH}$ profiles.

Deviations from perfect $\mathrm{CO}_{2}-\mathrm{H}_{2} \mathrm{O}$ equilibrium can be qualitatively observed if the $\mathrm{pH}$ during a batch experiment does not rise monotonically (e.g. see Fig. S29 in supplementary files for a nonmonotonic $\mathrm{pH}$ change during dissolution). Table 2 lists the values of the estimated parameters. The model parameters obtained for both particle structures are very similar. The updated model employing either particle structure was able to describe the dissolution trends with comparable accuracy.

For the sake of simplicity, all simulation plots shown in this study assume the homogeneous particle structure, though the discussion presented and the conclusions drawn are valid for both particle structures. Fig. 2 shows the quality of the fitting, where the experimental and simulated extents of dissolution, $X_{\mathrm{Mg}}$ and $X_{\mathrm{Si}}$, for experiments DB1 - DB18 are plotted. The model along with the fitted parameters was then used to predict the dissolution profiles of experiments DB19 - DB30. The model was able to predict the dissolution profiles at these new operating conditions with good accuracy. The experimental and simulation results for all experiments performed in this study are plotted and provided as supplementary files Fig. S1 - Fig. S30. In the following, we will discuss the various effects observed in the experiments and in the simulations.

\subsection{Influence of bicarbonate ions}

In the kinetic model that we have developed, bicarbonate ions affect the dissolution rate of the forsteritic silicate as described in Eq.(12). Experiments DB1 - DB9 were carried out in 
bicarbonate-rich solutions, and can be used for comparison with experiments DB10 - DB18 that were performed in bicarbonate-lean conditions. An enhancement in the dissolution rates for experiments in bicarbonate-rich solutions can already be observed from some of the experimental data in Table 1. As an example, let us compare the dissolution profiles of experiments DB1 and DB11 as shown in Fig. 3. The pH during the entire duration of experiment DB11 is lower than that of DB1. If the dissolution rate were dependent only on $a_{\mathrm{H}^{+}}, X_{\mathrm{Mg}}$ of experiment DB11 would be larger than that of DB1, contrary to the experimental measurement. From the value of $A_{1 \mathrm{x}} / A_{1}$ reported in Table 2, we obtain a minor enhancement in the dissolution rates of forsteritic silicate sites in the presence of bicarbonate ions by a factor of up to about five.

The effect of $\mathrm{CO}_{2}$ on the dissolution rate of forsterite has been studied by a few researchers. At acidic and near-neutral $\mathrm{pH}$ conditions, a small enhancement in the dissolution rate of forsterite in the presence of $\mathrm{CO}_{2}$ has been observed [21,22]. A statistical analysis of dissolution rates of forsterite in the presence and in the absence of $\mathrm{CO}_{2}$ was summarized by Rimstidt et al. [11]. Using the rate expressions tabulated for the two cases in that study, the dissolution rates are found to be enhanced by a factor of up to five in the presence of $\mathrm{CO}_{2}$, i.e. a value comparable to the one reported in this study. (Note that the authors, however, came to the opposite conclusion in the discussion part of their publication due to a misinterpretation of their data. The error was acknowledged by the corresponding author of that study [23]). However, it is also to be noted that the errors associated to the rate equations proposed in Rimstidt et al. are quite large. This made the authors be cautious about giving definite conclusions about the influence of $\mathrm{CO}_{2}$ on the dissolution rate of forsterite. Recently, an enhancement in the dissolution rates of lizardite in the presence of bicarbonate ions has been reported [17]. In our study, it turned out that the small effect of bicarbonate ions is quite significant in being able to describe the dissolution profiles of all experiments. Although the model was fitted to experimental data that had a value of the surface coverage $\theta_{\mathrm{v}_{\mathrm{x}}}$ of only up to 0.65 , the model is able to successfully predict dissolution profiles for higher surface coverages, namely up to 0.82 , as seen from the simulation shown in Fig. S20. The equilibrium constant for bicarbonate adsorption, $K_{\mathrm{HCO}_{3}}$, was assumed to be temperature-independent in this study in order to minimize the number of parameters estimated. The values associated to it for the two particle structures are an average value across a wide temperature range. The values obtained in this study are of the same order of magnitude as the value of the equilibrium constant for bicarbonate adsorption on brucite at $25^{\circ} \mathrm{C}$, i.e. 50 [13]. 


\subsection{Influence of $\mathrm{Mg}^{2+}$ ions and $\mathrm{SiO}_{2}(\mathrm{aq})$}

\subsubsection{Forsteritic silicate, $j=1$}

The dissolution rate of the forsteritic silicate is affected by the presence of $\mathrm{Mg}^{2+}$ ions and $\mathrm{SiO}_{2}$ (aq) through its reversible equilibrium reaction given by Eq.(12). To the best of our knowledge, only the theoretical study by Crundwell discusses the effect of forsterite equilibrium during its dissolution [24]. Crundwell assumes that $\mathrm{Mg}^{2+}$ ions do not affect forsterite dissolution based on the experimental observation reported by Olsen [25], and suggests that forsterite can never reach its true dissolution equilibrium. In the experimental study by Olsen, no inhibitory effect of $\mathrm{Mg}^{2+}$ ions was reported on forsterite dissolution rates up to a $c_{\mathrm{Mg}}$ of about $4 \mathrm{~mol} \mathrm{~kg}^{-1}$. Despite having high $\mathrm{Mg}^{2+}$ ion activities in those experimental studies, Olsen acknowledges the fact that the forsterite dissolution was still at far-from-equilibrium solution compositions due to the low $\mathrm{pH}$ and $\mathrm{SiO}_{2}(\mathrm{aq})$ values in those experiments. Hence, the assumption made by Crundwell on the effect of $\mathrm{Mg}^{2+}$ ions is questionable. In our model, we have expressed the reversibility of forsteritic silicate dissolution through its solubility equilibrium as given in Eq.(12), and assumed that forsterite can indeed reach its true dissolution equilibrium.

Fig. 4 shows an activity diagram where the logarithm of the activity ratio $\left(a_{\mathrm{Mg}^{2+}} / a_{\mathrm{H}^{+}}^{2}\right)$ is plotted against the logarithm of the activity product $\left(a_{\mathrm{Si}_{2} \text { (a) }} a_{\mathrm{H} 2 \mathrm{O}}^{2}\right)$. The solid black line represents the solubility of crystalline forsterite, and is obtained from Eq.(13) by setting $S_{1}=1$. The data represented through the markers in the plot are obtained from the experimentally measured solution compositions. The three green data points represent the solution composition of experiment DB18 at the three measured dissolution times, namely $60 \mathrm{~min}, 120 \mathrm{~min}$, and $180 \mathrm{~min}$. The arrow shows the direction along which the duration of the dissolution experiment increases. The solution composition during the entire duration of experiment DB18 is undersaturated with respect to forsterite. As a result, further dissolution of forsteritic silicate is possible in this scenario. The three red data points represent the three solution compositions from experiment DB9. It can be seen that the solution reaches the solubility of forsterite towards the end of the experiment. This would lead to the inhibition of further dissolution of the forsteritic silicate. This inhibition can also be observed from the experimental data reported by Werner et al. [3] for PDL particles. The blue data points correspond to solution compositions for the $90^{\circ} \mathrm{C}$ and $20 \%$ slurry density experiment reported in that study. It can be seen that the solution reaches, but does not exceed significantly the solubility composition of forsterite. The corresponding extent of dissolution, 
$X_{\mathrm{Mg}}$, reported for the experiment did not increase noticeably once the solution reached forsterite solubility. The decrease in $a_{\mathrm{SiO}_{2}(\mathrm{aaq})}$ in the plot is due to the precipitation of the secondary phase, namely quartz, as reported in that study [3]. Note that the experimental compositions lie slightly above the solubility composition of crystalline forsterite. This could be due to either an experimental uncertainty in measuring the solution compositions, or to the fact that the forsteritic silicate in the PDL particles is partly amorphous, and therefore exhibits a higher solubility than crystalline forsterite. These experiments show that the solution compositions during PDL dissolution can indeed reach the solubility composition of forsterite. The kinetic model developed in this study allows for this, and accounts for the slowing dissolution rate as equilibrium solubility is approached.

\subsubsection{Si-rich species, $j=2$}

The dissolution rate of Si-rich species was assumed to be affected by the presence of $\mathrm{Mg}^{2+}$ and $\mathrm{SiO}_{2}$ (aq) through its specific dissolution rate given by Eq.(24). $\mathrm{Mg}^{2+}$ ions were assumed to inhibit $r_{2}$ through the reversible reactions Eqs.(14) and (21). It was found that a combination of these two inhibitory mechanisms was necessary to describe the dissolution profiles at all temperatures, $T$, studied in this work. In particular, the inhibitory effect described by Eq.(21) dominates at $30^{\circ} \mathrm{C}$, and Eq.(14) dominates at $90^{\circ} \mathrm{C}$. $K_{\text {inh }}$ was assumed to be temperature independent in order to minimize the number of fitted parameters. In the absence of knowledge about the real nature of this Si-rich species, we found that the specific dissolution rate assumed to be given by Eq.(24) was necessary and sufficient to describe the dissolution profiles within the range of operating conditions of this study. Further experimental evidence on the nature of the Si-rich species would be required in order to critically analyze the values of the parameters obtained.

\section{Conclusions}

The rate limiting step for an aqueous $\mathrm{CO}_{2}$ mineralization process involving an abundant silicate mineral resource, like serpentine, is its dissolution to release $\mathrm{Mg}^{2+}$ ions into the solution. Through this publication series, we have conducted a systematic and thorough investigation of the dissolution kinetics of partially dehydroxylated lizardite particles. In order to understand the complex dissolution profiles exhibited by these dehydroxylated particles, which have nonhomogeneous physical morphologies and chemical properties [1,2], it became necessary to study 
their dissolution kinetics at a wide range of operating conditions. Since the overall objective of this research program is to develop an industrial $\mathrm{CO}_{2}$ mineralization process, kinetic models that account for time varying reactive surface areas have been developed that have allowed us to describe the non-steady state dissolution profiles. While the far-from-equilibrium kinetics gave insight into the inherent dissolution rate limitations associated to a silicate $[1,2]$, this nearequilibrium study allows us to understand the slowing dissolution rates as equilibrium solubility is approached. There is a need to study the dissolution rates both at far-from-equilibrium and at near-equilibrium operating conditions, as optimal solutions to overcome kinetic limitations will be different from those solutions overcoming limitations arising from equilibrium solubility. As an example, the kinetic rate constant for the dissolution of forsteritic silicate, $k_{1}$ increases with temperature, $T$, and this results in faster dissolution rates, $r_{1}$ at higher temperatures under far-from-equilibrium conditions [1,2]. However the equilibrium constant for the dissolution of forsterite, $K_{1}$, decreases with $T$ [20]. Therefore, as shown in Section 4.2.1, this leads to slower dissolution rates and dissolution extents, $X_{\mathrm{Mg}}$, at $T=90^{\circ} \mathrm{C}$ and at solution compositions relevant for $\mathrm{CO}_{2}$ mineralization. By studying far-from-equilibrium dissolution kinetics independent of the near-equilibrium dissolution kinetics, we are able to distinguish between the consequences on $r_{1}$ in Eq.(12) arising from the parameters, $k_{1}$ and $K_{1}$.

Mineral dissolution is a complicated process and often involves a multitude of phenomena. In this study, we have made several assumptions and simplifications to develop the equations that describe experimentally measured dissolution rates over a wide range of operating conditions. Nevertheless such a simplified model allows for an accurate quantitative description of both the far-from-equilibrium and the near-equilibrium dissolution profiles, within the range of operating conditions considered in this study, and in the absence of passivating amorphous silica layers. Precipitating amorphous silica has been shown not to completely inhibit the dissolution of PDL particles [3]. The near-equilibrium kinetic model developed in this study is necessary for any further study on the effects of passivation layers, in order to be able to distinguish between the equilibrium limitations for the dissolving silicate and transport limitations associated to the passivation layer. The kinetic model could also be used to design and optimize a multi-step $\mathrm{CO}_{2}$ mineralization process that avoids the formation of a non-negligible passivation layer. 


\section{Notation}

a activity of aqueous solute [-]

$A \quad$ pre-exponential term in Arrhenius equation $\left[\mathrm{mol} \mathrm{m}^{-2} \mathrm{~min}^{-1}\right.$ ]

c concentration of aqueous solute $\left[\mathrm{mol} \mathrm{kg}^{-1}\right]$

D diffusion coefficient $\left[\mathrm{m}^{2} \mathrm{~s}^{-1}\right]$

$E_{\mathrm{a}} \quad$ activation energy $\left[\mathrm{kJ} \mathrm{mol}^{-1}\right]$

$f_{\mathrm{CO}_{2}} \quad$ fugacity of $\mathrm{CO}_{2}$ [bar]

$F \quad$ Faraday constant $\left[\mathrm{C} \mathrm{mol}^{-1}\right]$

$k_{1} \quad$ rate constant for the dissolution of a ligand-free forsteritic silicate site under acidic $\mathrm{pH}$ conditions $\left[\mathrm{mol} \mathrm{m} \mathrm{min}^{-1}\right.$ ]

$k_{1 \mathrm{x}} \quad$ rate constant for the dissolution of bicarbonate-adsorbed forsteritic silicate site under acidic $\mathrm{pH}$ conditions $\left[\mathrm{mol} \mathrm{m} \mathrm{min}^{-1}\right.$ ]

$\tilde{k}_{1} \quad$ rate constant for the dissolution of a ligand-free forsteritic silicate site under basic $\mathrm{pH}$ conditions $\left[\mathrm{mol} \mathrm{m}^{-2} \mathrm{~min}^{-1}\right.$ ]

$\tilde{k}_{1 \mathrm{x}} \quad$ rate constant for the dissolution of bicarbonate-adsorbed forsteritic silicate site under basic $\mathrm{pH}$ conditions $\left[\mathrm{mol} \mathrm{m} \mathrm{min}^{-1}\right.$ ]

$k_{2}^{-} \quad$ forward rate constant for deprotonated site promoted dissolution of the Si-rich species $\left[\mathrm{mol} \mathrm{m}^{-2} \mathrm{~min}^{-1}\right.$ ]

$k_{2}^{\prime-} \quad$ backward rate constant for deprotonated site promoted dissolution of the Si-rich species $\left[\mathrm{mol} \mathrm{m}^{-2} \mathrm{~min}^{-1}\right.$ ]

$K_{\text {des }} \quad$ equilibrium constant for proton desorption [-]

$K_{\mathrm{ex}} \quad$ equilibrium constant for proton- $\mathrm{Mg}^{2+}$ ion-exchange [-]

$K_{\mathrm{HCO}_{3}} \quad$ temperature-independent equilibrium constant for bicarbonate ion adsorption [-]

$K_{\text {inh }} \quad$ temperature-independent equilibrium constant for adsorption of $\mathrm{Mg}$ ions on Si-rich species [-]

$K_{j} \quad$ equilibrium constant for dissolution of silicate species $j[-]$

$K_{\mathrm{Si}} \quad$ equilibrium constant for the dissolution of amorphous silica [-]

$m \quad$ Temkin's average stoichiometric number [-]

$N \quad$ total number of moles of a solute remaining in the entire PSD of dissolving particles [mol]

$p \mathrm{CO}_{2} \quad$ partial pressure of $\mathrm{CO}_{2}$ [atm]

$\mathrm{pH}^{*} \quad$ transition $\mathrm{pH}$ for forsterite dissolution [-] 


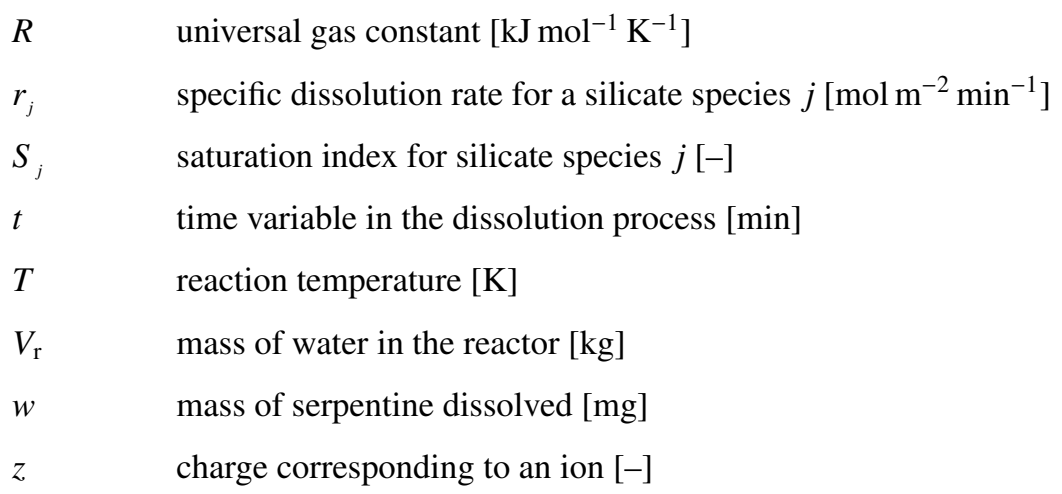

\section{Greek Letters}

$\gamma \quad$ the Debye-Hückel activity coefficient [-]

$\delta \quad$ correction factor [-]

$\Delta H_{\mathrm{ex}}^{0} \quad$ enthalpy of reaction for the ion-exchange process [ $\left[\mathrm{kJ} \mathrm{mol}^{-1}\right]$

$\eta \quad$ stoichiometric coefficient for $\mathrm{Mg}[-]$

$\kappa \quad$ solution conductivity $\left[\mathrm{mS} \mathrm{cm}^{-1}\right]$

$\lambda_{\mathrm{eq}}^{0} \quad$ limiting equivalent conductance $\left[\mathrm{mS} \mathrm{L} \mathrm{cm}^{-1} \mathrm{eq}^{-1}\right]$

$\lambda_{\mathrm{m}}^{0} \quad$ limiting molar conductance $\left.\left[\mathrm{mS} \mathrm{L} \mathrm{cm}^{-1} \mathrm{~mol}^{-1}\right)\right]$

$\mu_{j} \quad$ stoichiometric index for $\mathrm{Mg}$ in a silicate species $j[-]$

$\mu_{\mathrm{s}} \quad$ viscosity of the solution [Pa s]

$\sigma_{j} \quad$ stoichiometric index for $\mathrm{Si}$ in a silicate species $j[-]$

$\theta_{\mathrm{v}_{\mathrm{x}}} \quad$ fraction of bicarbonate-adsorbed forsteritic sites [-]

$\theta_{\rightarrow \mathrm{SiO}^{-}} \quad$ fraction of $>\mathrm{SiO}^{-}$sites in $\mathrm{Si}$-rich species [-]

\section{Index}

j silicate species in a particle

$l \quad$ ion in solution

\section{Others}

PDL partially dehydroxylated lizardite 


$\begin{array}{ll}\text { PSD } & \text { particle size distribution } \\ \mathrm{V} & \text { bicarbonate-free forsteritic site } \\ \mathrm{V}_{\mathrm{x}} & \text { bicarbonate-adsorbed forsteritic site }\end{array}$

\section{Acknowledgments}

Financial support from the Foundation Claude \& Giuliana (Basel, $\mathrm{CH}$ ) and the Swiss National Science Foundation is gratefully acknowledged.

\section{Appendix A Conductivity Probe Calibration}

A number of studies exist in literature that describe the evolution of solution conductivity, $\kappa$, with solution composition. McCleskey et al. have summarized and compared the different methods that exist in literature [26]. Among these methods, we have chosen the model developed by Apello [27]. The choice was dictated by the fact that only this model covered most of the ionic species dealt with in our study. The equations used in this method is summarized below.

The conductivity of the solution composed of different ions $l$ at a given temperature $T$ is given as [27]

$$
\kappa=\sum_{l}\left(\lambda_{\mathrm{eq}, l}^{0}\left|z_{l}\right| \gamma_{l}^{\delta_{l}} c_{l}\right)
$$

where $\lambda_{\mathrm{eq}, l}^{0}$ is the limiting equivalent conductance of the ion $l ; z_{l}$ is the charge of the ion $l ; \gamma_{l}$ is the Debye-Hückel activity coefficient for the ion $l$ and was obtained from EQ3/6 [20]; $\delta_{l}$ is a correction factor given as $\delta_{l}=0.6 /\left|z_{l}\right|^{0.5}$; and $c_{l}$ is the concentration of the ion $l$.

The limiting equivalent conductance is calculated from the definition of mobility of an ion [28] and the Nernst-Einstein equation:

$$
\lambda_{\mathrm{m}, l}^{0}=\frac{\left|z_{l}\right|^{2} F^{2}}{R T} D_{l}=\lambda_{\mathrm{eq}, l}^{0}\left|z_{l}\right|
$$

where $\lambda_{\mathrm{m}, l}^{0}$ is the limiting molar conductance of ion $l ; F$ is the Faraday constant; $D_{l}$ is the diffusion coefficient for the ion $l$. 
The temperature dependence of $D_{l}$ is given by

$$
\left.\left.D_{l}\right|_{T} \approx D_{l}\right|_{298.15} \frac{T}{298.15} \frac{\left.\mu_{\mathrm{s}}\right|_{298.15}}{\left.\mu_{\mathrm{s}}\right|_{T}}
$$

where $\mu_{\mathrm{s}}$ is the dynamic viscosity of the solution.

From Eq.A.2 and A.3, we see that

$$
\frac{\left.\lambda_{\mathrm{eq}, l}^{0}\right|_{T}}{\left.\lambda_{\mathrm{eq}, l}^{0}\right|_{298.15}} \approx \frac{\left.\mu_{\mathrm{s}}\right|_{298.15}}{\left.\mu_{\mathrm{s}}\right|_{T}}
$$

and this ratio is independent of the type of ion $l$. Given literature data for $\lambda_{\text {eq, } l \text { 298.15 }}^{0}[29,30]$, and approximating the viscosity of the relatively dilute solution, $\mu_{\mathrm{s}}$, to the viscosity of water at any temperature $T$, we can determine $\lambda_{\text {eq }, l}^{0} l_{T}$ at the different temperatures, $T$, in our experiments. The approximation in Eq.(A.4) was found to be valid for all ions, except for protons and $\mathrm{Mg}^{2+}$ ions. In the case of protons, its diffusivity arises not only due to Brownian motion, but also includes the Grotthuss mechanism [31]. Hence $\left.\lambda_{\text {eq, } \mathrm{H}^{+}}^{0}\right|_{T}$ and $\left.\lambda_{\text {eq, } \mathrm{Mg}^{2+}}^{0}\right|_{T}$ were estimated at each temperature $T$ through independent calibration experiments.

Solutions with different but known compositions of $\mathrm{Mg}(\mathrm{aq})$ were produced from the filtrate of a pre-dissolved PDL slurry solution. The solutions were equilibrated with respect to $T$ and $f_{\mathrm{CO}_{2}}$ in the same reactor set-up described in the study. The experimental conductivity of these solutions were then recorded. Note that no pre-programmed temperature compensation to the measured conductivity was applied in this study. The contribution of silicic acid to the conductivity was neglected as silicic acid does not dissociate under $\mathrm{pH}$ conditions obtained in this work. Presence of other trace-metal ions (like $\mathrm{Fe}^{2+}$ impurity that is present in PDL particles) in the solution was also neglected. The theoretical values of $\kappa$ was estimated from Eqs.(A.1) - (A.4) with the values of $\left.\lambda_{\mathrm{eq}, H^{+}}^{0}\right|_{T}$ and $\left.\lambda_{\mathrm{eq}, \mathrm{Mg}^{2+}}^{0}\right|_{T}$ fitted to the calibration experimental data. Fig. A1 shows the result from the calibration procedure at the three temperatures $T$ of 30,60 , and $90^{\circ} \mathrm{C}$ and three different inlet gas compositions. The complete set of parameters used to calculate the $\kappa$ is tabulated in Table A1.

\section{References}

[1] M. Werner, S. Hariharan, D. Zingaretti, R. Baciocchi, M. Mazzotti, Dissolution of dehydroxylated lizardite at flue gas conditions: I. Experimental study, Chem. Eng. J. 241 (2014) 301-313. 
[2] S. Hariharan, M. Werner, M. Hänchen, M. Mazzotti, Dissolution of dehydroxylated lizardite at flue gas conditions: II. Kinetic modeling, Chem. Eng. J. 241 (2014) 314-326.

[3] M. Werner, S. Hariharan, M. Mazzotti, Flue gas $\mathrm{CO}_{2}$ mineralization using thermally activated serpentine: From single-to double-step carbonation, Phys. Chem. Chem. Phys. 16 (2014) 24978-24993.

[4] O. S. Pokrovsky, J. Schott, Kinetics and mechanism of forsterite dissolution at $25^{\circ} \mathrm{C}$ and pH from 1 to 12 , Geochim. Cosmochim. Ac. 64 (2000) 3313-3325.

[5] E. H. Oelkers, J. Schott, An experimental study of enstatite dissolution rates as a function of $\mathrm{pH}$, temperature, and aqueous $\mathrm{Mg}$ and $\mathrm{Si}$ concentration, and the mechanism of pyroxene/pyroxenoid dissolution, Geochim. Cosmochim. Ac. 65 (2001) 1219-1231.

[6] P. Aagaard, H. C. Helgeson, Thermodynamic and kinetic constraints on reaction rates among minerals and aqueous solutions. I. Theoretical considerations, Am. J. Sci. 282 (1982) 237-285.

[7] D. Daval, O. Sissmann, N. Menguy, G. D. Saldi, F. Guyot, I. Martinez, J. Corvisier, B. Garcia, I. Machouk, K. G. Knauss, et al., Influence of amorphous silica layer formation on the dissolution rate of olivine at $90^{\circ} \mathrm{C}$ and elevated pCO${ }_{2}$, Chem. Geol. 284 (1) (2011) 193-209.

[8] H. Béarat, M. J. McKelvy, A. V. Chizmeshya, D. Gormley, R. Nunez, R. Carpenter, K. Squires, G. H. Wolf, Carbon sequestration via aqueous olivine mineral carbonation: role of passivating layer formation, Environ. Sci. Technol. 40 (15) (2006) 4802-4808.

[9] O. Sissmann, F. Brunet, I. Martinez, F. Guyot, A. Verlaguet, Y. Pinquier, D. Daval, Enhanced olivine carbonation within a basalt as compared to single-phase experiments: Reevaluating the potential of $\mathrm{CO}_{2}$ mineral sequestration, Environ. Sci. Technol. 48 (2014) 5512-5519.

[10] D. Daval, I. Martinez, J. Corvisier, N. Findling, B. Goffé, F. Guyot, Carbonation of ca-bearing silicates, the case of wollastonite: experimental investigations and kinetic modeling, Chem. Geol. 265 (1) (2009) 63-78.

[11] J. D. Rimstidt, S. L. Brantley, A. A. Olsen, Systematic review of forsterite dissolution rate data, Geochim. Cosmochim. Ac. 99 (2012) 159-178.

[12] V. Prigiobbe, M. Mazzotti, Dissolution of olivine in the presence of oxalate, citrate, and $\mathrm{CO}_{2}$ at $90^{\circ} \mathrm{C}$ and $120^{\circ} \mathrm{C}$, Chem. Eng. Sci. 66 (24) (2011) 6544-6554.

[13] O. S. Pokrovsky, J. Schott, A. Castillo, Kinetics of brucite dissolution at $25^{\circ} \mathrm{C}$ in the presence of organic and inorganic ligands and divalent metals, Geochim. Cosmochim. Ac. 69 (4) (2005) 905-918.

[14] B. A. Fleming, Kinetics of reaction between silicic acid and amorphous silica surfaces in NaCl solutions, J. Colloid Interf. Sci. 110 (1986) 40-64.

[15] R. K. Iler, The chemistry of silica: solubility, polymerization, colloid and surface properties, and biochemistry, Wiley New York, 1979.

[16] W. Stumm, Reactivity at the mineral-water interface: dissolution and inhibition, Colloid Surface A 120 (1) (1997) 143-166.

[17] D. Daval, R. Hellmann, I. Martinez, S. Gangloff, F. Guyot, Lizardite serpentine dissolution kinetics as a function of $\mathrm{pH}$ and temperature, including effects of elevated $p \mathrm{CO}_{2}$, Chem. Geol. 351 (2013) 245-256.

[18] A. Covington, P. Whalley, W. Davison, Recommendations for the determination of $\mathrm{pH}$ in low ionic strength fresh waters, Pure. Appl. Chem. 57 (6) (1985) 877-886.

[19] G. Marinenko, R. C. Paule, W. F. Koch, M. Knoerdel, Effect of variables on pH measurement in acid-rain-like 
solutions as determined by ruggedness tests, J. Res. Nat. Bur. Stand. 91 (1986) 17-22.

[20] T. Wolery, EQ3/6 - Software for Geochemical Modeling Version 8.0, UCRL-CODE-2003-009, Lawrence Livermore National Laboratory, Livermore, California (2002).

[21] M. Hänchen, V. Prigiobbe, G. Storti, T. Seward, M. Mazzotti, Dissolution kinetics of fosteritic olivine at 90-150 ${ }^{\circ} \mathrm{C}$ including effects of the presence of $\mathrm{CO}_{2}$, Geochim. Cosmochim. Ac. 70 (2006) 4403-4416.

[22] S. V. Golubev, O. S. Pokrovsky, J. Schott, Experimental determination of the effect of dissolved $\mathrm{CO}_{2}$ on the dissolution kinetics of $\mathrm{Mg}$ and Ca silicates at 25 ${ }^{\circ} \mathrm{C}$, Chem. Geol. 217 (2005) 227-238.

[23] J. D. Rimstidt, personal communication, August 132015.

[24] F. Crundwell, The mechanism of dissolution of forsterite, olivine and minerals of the orthosilicate group, Hydrometallurgy 150 (2014) 68-82.

[25] A. A. Olsen, Forsterite dissolution kinetics: applications and implications for chemical weathering, Ph.D. thesis, Virginia Polytechnic Institute and State University (2007).

[26] R. B. McCleskey, D. K. Nordstrom, J. N. Ryan, Comparison of electrical conductivity calculation methods for natural waters, Limnol Oceanogr Methods 10 (11) (2012) 952-967.

[27] C. A. J. Appelo, Specific conductance: how to calculate, to use, and the pitfalls, http://www .hydrochemistry . eu/exmpls/sc.html (2010, accessed on August 6, 2015).

[28] W. J. Hamer, H. J. DeWane, Electrolytic conductance and the conductances of the halogen acids in water, Vol. 33 , US Government Printing Office, 1970.

[29] R. L. Miller, W. L. Bradford, N. E. Peters, Specific conductance: theoretical considerations and application to analytical quality control, US Government Printing Office, 1988.

[30] G. Marion, K. Babcock, Predicting specific conductance and salt concentration in dilute aqueous solutions., Soil Sci 122 (4) (1976) 181-187.

[31] N. Agmon, The grotthuss mechanism, Chem Phys Lett 244 (5) (1995) 456-462. 


\section{List of figure captions}

Fig. 1 - Exemplary experiment DB10 consisting of three experimental runs with different overall dissolution time, i.e. $60 \mathrm{~min}$ (red), $120 \mathrm{~min}$ (blue), and $180 \mathrm{~min}$ (green). The reactor solution was equilibrated during $-60 \min \leq t \leq 0$ min with respect to $T$ and $f_{\mathrm{CO}_{2}}$ prior to the start of dissolution. (left) The evolution of the experimental solution conductivity, $\kappa$, during the three experimental runs and (right) the measured values of $c_{\mathrm{Mg}}$ (circles) and $c_{\mathrm{Si}}$ (triangles) from manual sampling, and the values of $c_{\mathrm{Mg}}$ obtained from conductivity measurements (crosses) at the end of each experimental run are shown.

Fig. 2 - Experimental (circles and triangles) and simulated (lines) extents of dissolution, $X_{\mathrm{Mg}}$ and $X_{\mathrm{Si}}$, for experiments DB1 - DB9 (top) and DB10 - DB18 (bottom), operated at 30,60 , and $90^{\circ} \mathrm{C}$. At each temperature $T$, experiments were performed by bubbling pure $\mathrm{CO}_{2}$ (red), $10 \% \mathrm{CO}_{2}$ in $\mathrm{N}_{2}$ (blue), and $2.5 \% \mathrm{CO}_{2}$ in $\mathrm{N}_{2}$ (green).

Fig. 3 - Experimental (markers) and simulated (lines) dissolution profiles of experiments DB1 (red) and DB11 (blue). The extents of dissolution, $X_{\mathrm{Mg}}$ (circles and line) and $X_{\mathrm{Si}}$ (triangles and broken line) and the corresponding experimental (circles) and simulated (lines) $\mathrm{pH}$ are shown.

Fig. 4 - Activity diagram showing the solubility of forsterite (black line) and the experimental solution compositions for experiment DB18 (green), DB9 (red), and the $90^{\circ} \mathrm{C}$ and $20 \%$ slurry density single-step experiment reported elsewhere [3] (blue). The arrows indicate the direction along which dissolution time $t$ evolves.

Fig. A1- Experimental (circles) and calculated (lines) values of $\kappa$ in the conductivity probe calibration experiments at 30,60 , and $90^{\circ} \mathrm{C}$ and $1 \mathrm{~atm}$ total pressure. At each temperature $T$, solution was equilibrated by bubbling gas of three different gas compositions, namely pure $\mathrm{CO}_{2}$ (red), $10 \% \mathrm{CO}_{2}$ in $\mathrm{N}_{2}$ (blue), and $2.5 \% \mathrm{CO}_{2}$ in $\mathrm{N}_{2}$ (green). 


\section{List of table captions}

Table 1 - Operating conditions for all dissolution experiments. The tabulated activities and saturation indices are computed with EQ3/6 v8.0a [20]. All dissolution experiments were performed by dissolving the $20-63 \mu \mathrm{m}$ size-fraction particles in ultrapure de-ionized water equilibrated with a certain $f_{\mathrm{CO}_{2}}$, unless indicated otherwise.

Table 2 - Model parameters for homogeneous and heterogeneous particle structures.

Table A1- Parameters for conductivity probe calibration. 

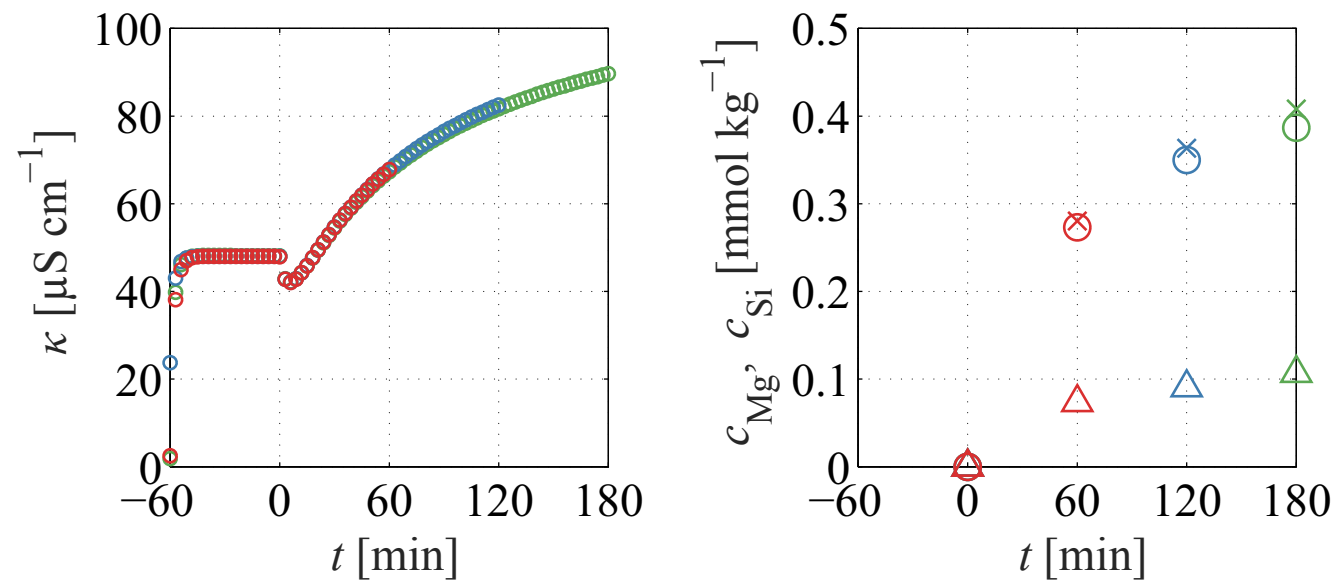

Fig.1: Exemplary experiment DB10 consisting of three experimental runs with different overall dissolution time, i.e. $60 \mathrm{~min}$ (red), $120 \mathrm{~min}$ (blue), and $180 \mathrm{~min}$ (green). The reactor solution was equilibrated during $-60 \mathrm{~min} \leq t \leq 0 \mathrm{~min}$ with respect to $T$ and $f_{\mathrm{CO}}$, prior to the start of dissolution. (left) The evolution of the experimental solution conductivity, $\kappa$, during the three experimental runs and (right) the measured values of $c_{\mathrm{Mg}}$ (circles) and $c_{\mathrm{Si}}$ (triangles) from manual sampling, and the values of $c_{\mathrm{Mg}}$ obtained from conductivity measurements (crosses) at the end of each experimental run are shown. 

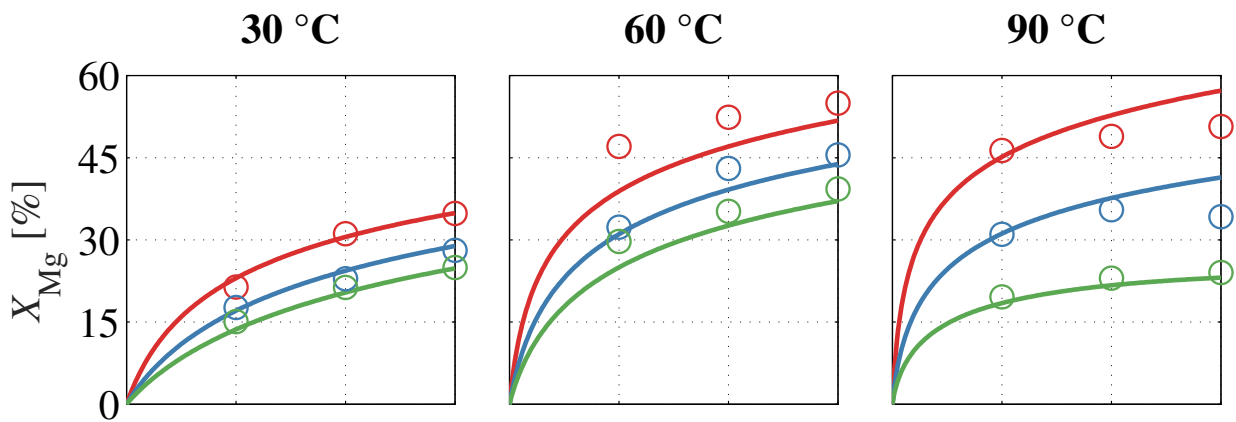

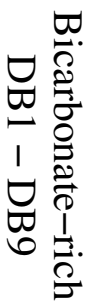
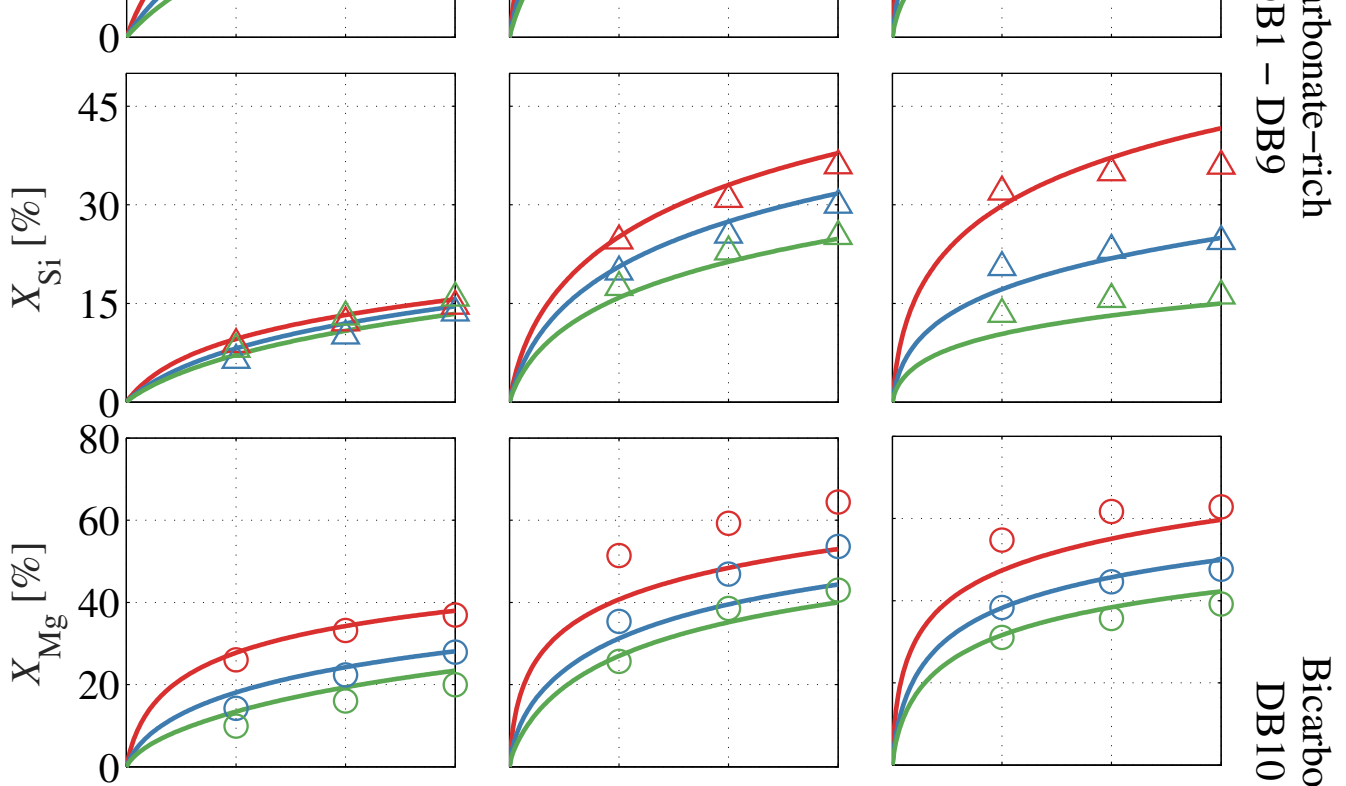

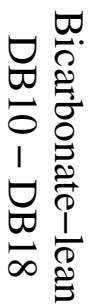
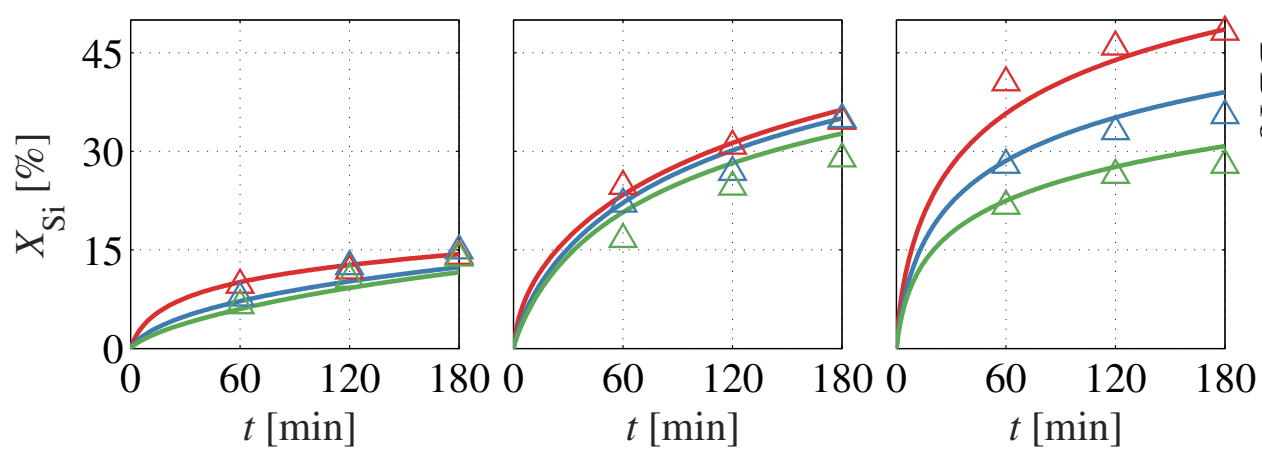

Fig. 2: Experimental (circles and triangles) and simulated (lines) extents of dissolution, $X_{\mathrm{Mg}}$ and $X_{\mathrm{Si}}$, for experiments DB1 - DB9 (top) and DB10 - DB18 (bottom), operated at 30, 60, and $90^{\circ} \mathrm{C}$. At each temperature $T$, experiments were performed by bubbling pure $\mathrm{CO}_{2}$ (red), $10 \% \mathrm{CO}_{2}$ in $\mathrm{N}_{2}$ (blue), and $2.5 \% \mathrm{CO}_{2}$ in $\mathrm{N}_{2}$ (green). 

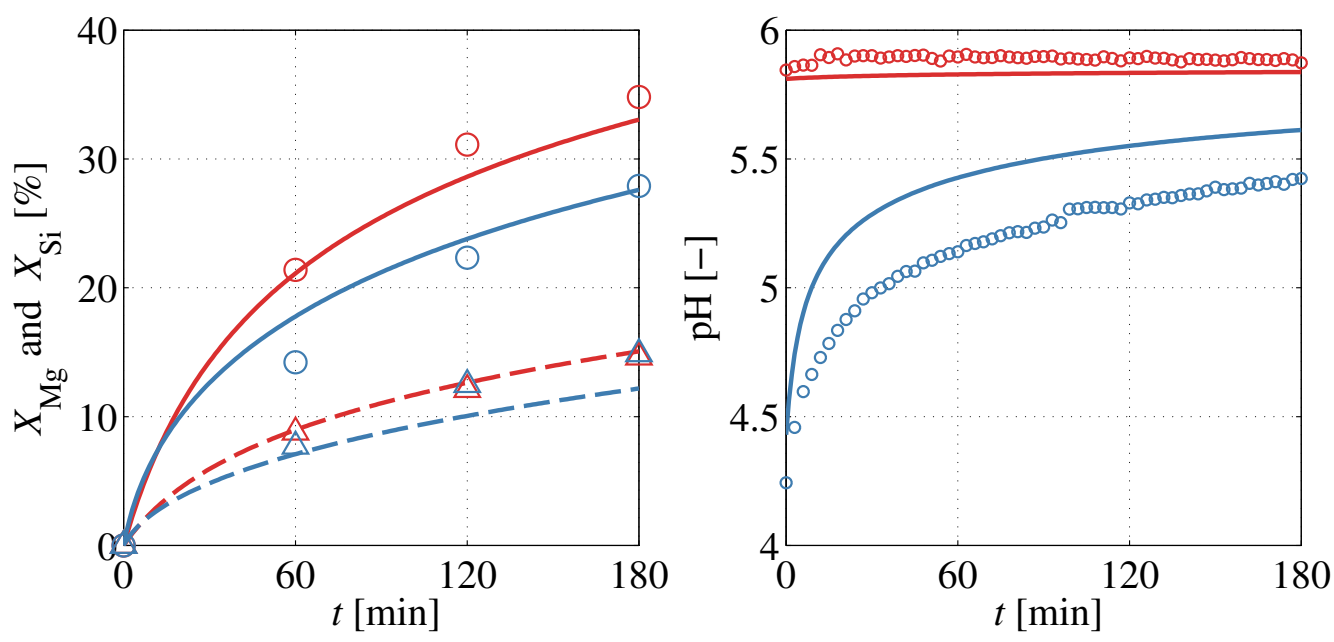

Fig. 3: Experimental (markers) and simulated (lines) dissolution profiles of experiments DB1 (red) and DB11 (blue). The extents of dissolution, $X_{\mathrm{Mg}}$ (circles and line) and $X_{\mathrm{Si}}$ (triangles and broken line) and the corresponding experimental (circles) and simulated (lines) $\mathrm{pH}$ are shown. 


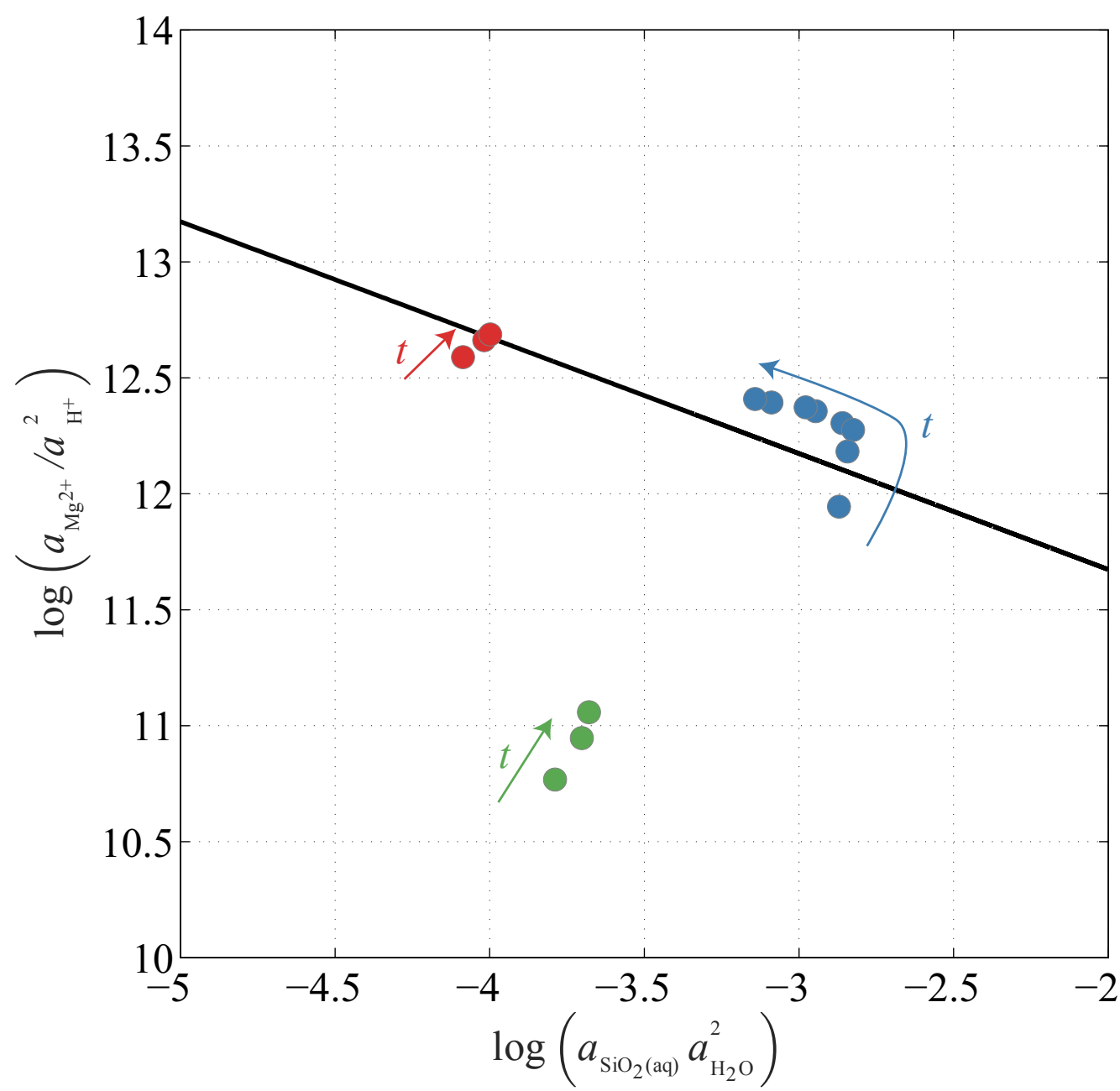

Fig. 4: Activity diagram showing the solubility of forsterite (black line) and the experimental solution compositions for experiment DB18 (green), DB9 (red), and the $90{ }^{\circ} \mathrm{C}$ and $20 \%$ slurry density single-step experiment reported elsewhere [3] (blue). The arrows indicate the direction along which dissolution time $t$ evolves. 

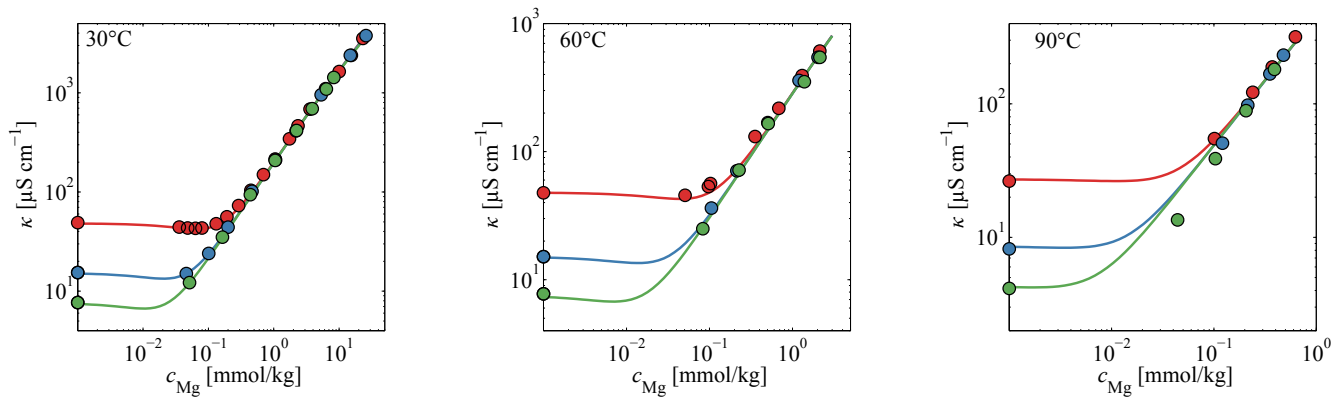

Fig. A1: Experimental (circles) and calculated (lines) values of $\kappa$ in the conductivity probe calibration experiments at 30,60 , and $90^{\circ} \mathrm{C}$ and $1 \mathrm{~atm}$ total pressure. At each temperature $T$, solution was equilibrated by bubbling gas of three different gas compositions, namely pure $\mathrm{CO}_{2}$ (red), $10 \% \mathrm{CO}_{2}$ in $\mathrm{N}_{2}$ (blue), and $2.5 \% \mathrm{CO}_{2}$ in $\mathrm{N}_{2}$ (green). 


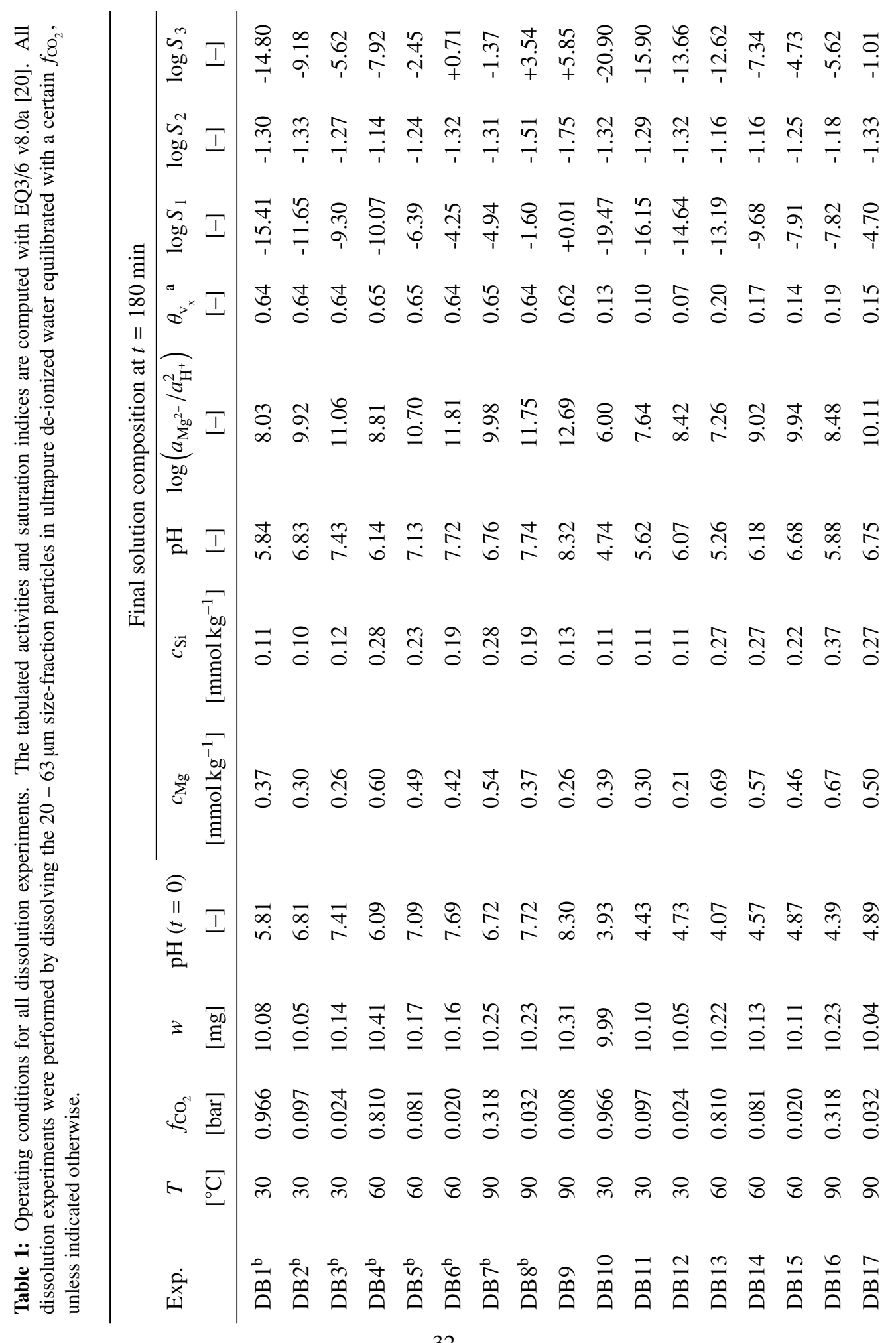




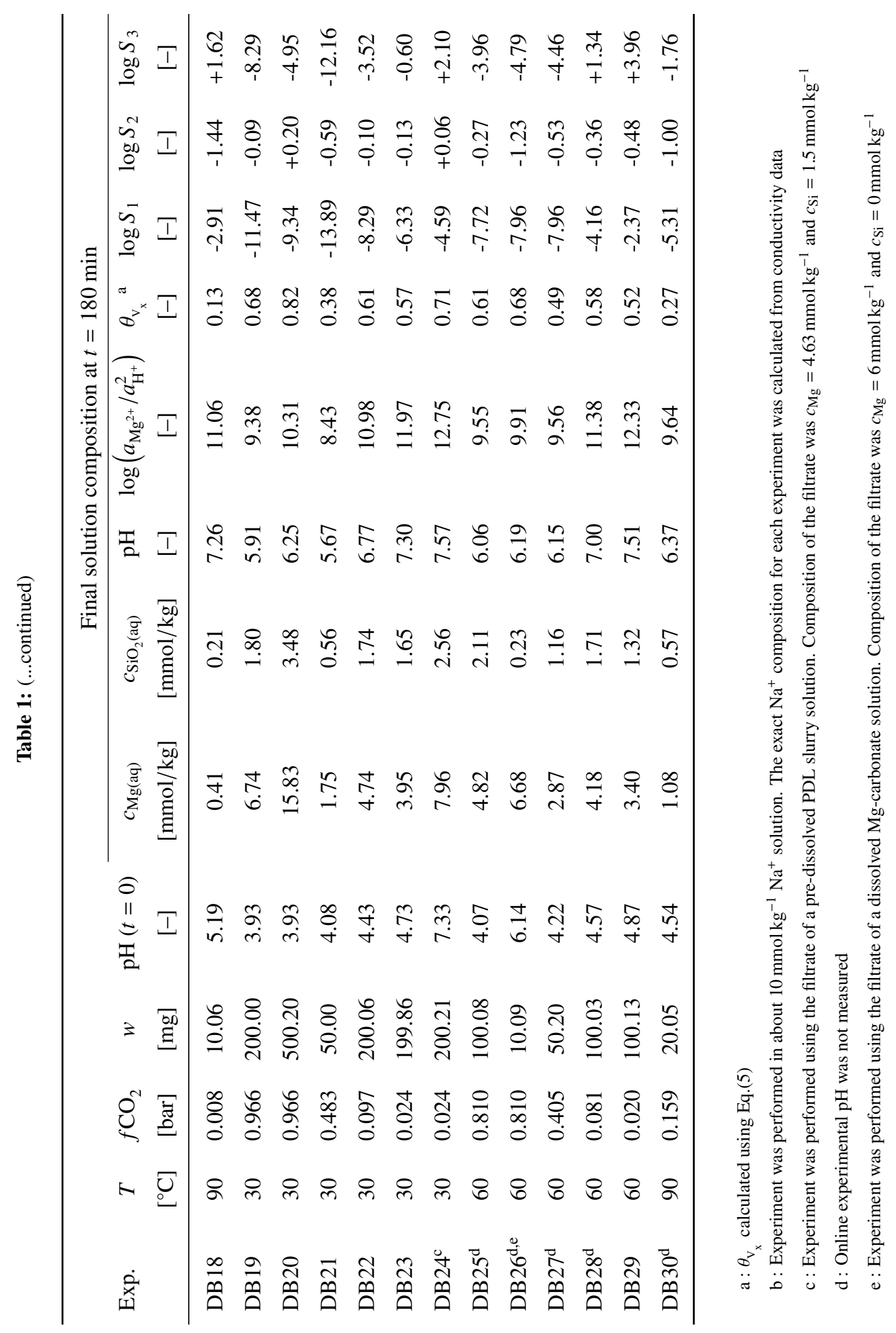


Table 2: Model parameters for homogeneous and heterogeneous particle structures.

\begin{tabular}{lcccccc}
\hline & $\begin{array}{c}A_{1 \mathrm{x}} / A_{1} \\
{[-]}\end{array}$ & $\begin{array}{c}K_{\mathrm{HCO}_{3}} \\
{[-]}\end{array}$ & $\begin{array}{c}m \\
{[-]}\end{array}$ & $\begin{array}{c}K_{\mathrm{ex}}\left(25^{\circ} \mathrm{C}\right) \\
{[-]}\end{array}$ & $\begin{array}{c}\Delta H_{\mathrm{ex}}^{0} \\
{\left[\mathrm{~kJ} \mathrm{~mol}^{-1}\right]}\end{array}$ & $\begin{array}{c}K_{\text {inh }} \\
{[-]}\end{array}$ \\
\hline Homogeneous & 5.35 & 187 & 12.0 & $2.16 \times 10^{10}$ & -121 & $4.25 \times 10^{-4}$ \\
Heterogeneous & 5.24 & 226 & 11.6 & $3.07 \times 10^{10}$ & -113 & $4.76 \times 10^{-4}$ \\
\hline
\end{tabular}


Table A1: Parameters for conductivity probe calibration.

\begin{tabular}{ccccccccc}
\hline & & \multicolumn{7}{c}{$\lambda_{\text {eq }, l}^{0}[\mathrm{mS} \mathrm{L} /(\mathrm{cm}$ eq. $)]$} \\
\cline { 3 - 9 }$T\left[{ }^{\circ} \mathrm{C}\right]$ & $\mu_{\mathrm{s}}[-]$ & $\mathrm{Na}^{+}$ & $\mathrm{HCO}_{3}{ }^{-}$ & $\mathrm{CO}_{3}{ }^{2-}$ & $\mathrm{OH}^{-}$ & $\mathrm{MgHCO}_{3}{ }^{+}$ & $\mathrm{H}^{+}$ & $\mathrm{Mg}^{2+}$ \\
\hline $25^{\mathrm{a}}$ & 0.890 & 50.1 & 44.5 & 69.3 & 197.8 & 35.5 & 349.8 & 53.1 \\
$30^{\mathrm{b}}$ & 0.798 & 55.9 & 49.6 & 77.3 & 220.7 & 39.6 & 359.0 & 56.8 \\
$60^{\mathrm{b}}$ & 0.466 & 95.7 & 85.0 & 132.4 & 377.9 & 67.8 & 478.6 & 68.61 \\
$90^{\mathrm{b}}$ & 0.315 & 141.6 & 125.7 & 195.8 & 558.9 & 100.3 & 540.5 & 121.9 \\
\hline $\mathrm{a}: \lambda_{\mathrm{eq}, l}^{0}$ data obtained from literature $[29,30]$ \\
$\mathrm{b}: \lambda_{\mathrm{eq}, l}^{0}$ for all ions $l$ except $\mathrm{H}^{+}$and $\mathrm{Mg}^{2+}$ are calculated from Eq.(A.4)
\end{tabular}


Figure4
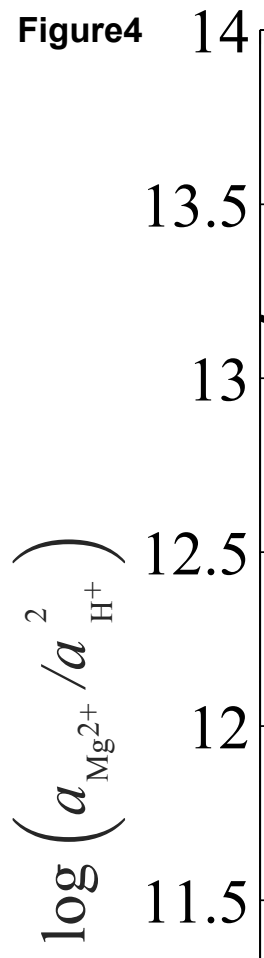

13.5

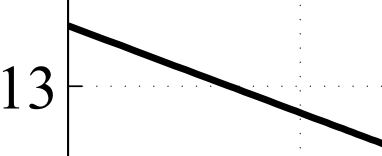

12.5

i I

12

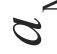

응 11.5

11

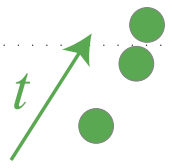

10.5

10

$-5$

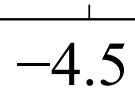

$-4 \quad-3.5$

$-2.5$

$-2$

$\log \left(a_{\mathrm{SiO}_{2} \text { (aq) }} a_{\mathrm{H}_{2} \mathrm{O}}^{2}\right)$ 

Molecule1/Eq18
$O$

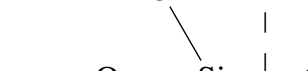

$\mathrm{O}-\mathrm{Si} \frac{\mathrm{I}}{\mathrm{O}} \mathrm{OH}$

$\mathrm{O}-\mathrm{Si}-\mathrm{O}^{-}$

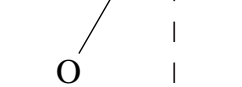

$\mathrm{O}-\mathrm{Si}-\mathrm{OH}$
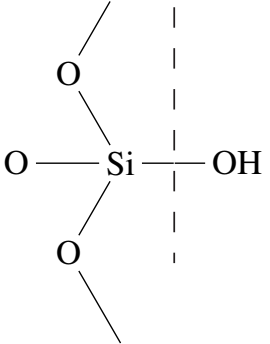

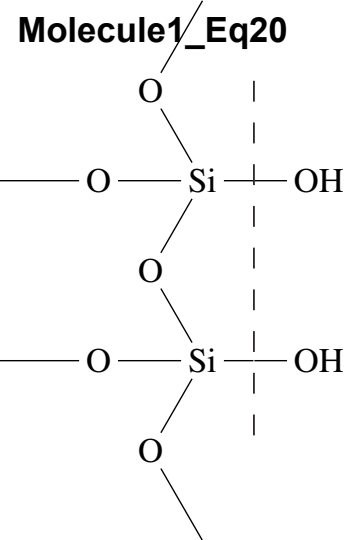

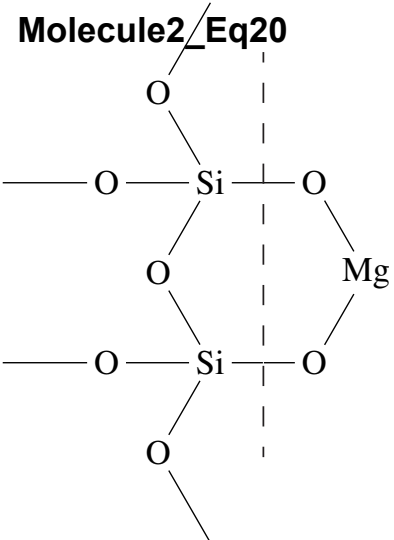
Molecule2/Eq18
$\mathrm{O}$

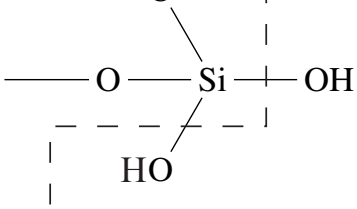

$\mathrm{OH}$

।

I $\mathrm{HO}$

$---t-\urcorner$

$\mathrm{O}-\mathrm{Si} \longrightarrow \mathrm{OH}$
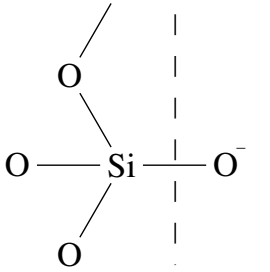

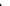

